\title{
Habitat management of the endemic and critical endangered Montseny Brook Newt (Calotriton arnoldi)
}

\author{
DanielGuinart ${ }^{1}$, Sonia Solórzano ${ }^{1}$, Fèlix Amat ${ }^{2}$, Jordina Grau ${ }^{1}$, Daniel Fernández-Guiberteau ${ }^{3}$ and Albert Montori ${ }^{3 *}$
}

1 Oficina Tècnica de Parcs Naturals. Diputació de Barcelona. The Montseny Natural Park and Biosphere Reserve. Masia Mariona. Ctra. 5119, Km. 2,5 (Mosqueroles). 08479 Fogars de Montclús. Barcelona. Spain. guinartsd@diba.cat

2 Àrea d'Herpetologia, BiBIO, Museu de Granollers - Ciències Naturals. Palaudàries 102, Granollers 08402, Barcelona. Spain. felixamat09@gmail.com

3 CREAC. Centre de Recerca i Educació ambiental de Calafell. GRENP/Aj. 43882 Calafell. Tarragona. Spain. info@guibernatura.com

* Correspondence: amontori@gmail.com (DG, SS, FA, DFG and AM)

\begin{abstract}
Calotriton arnoldi is an endemic amphibian inhabiting Montseny Natural Park and Biosphere Reserve (PNRBM). It was recognized as a new taxon in 2005 by means of genetic and morphological analyses and, due to its small distribution range and population size, it was listed as "Critically endangered (CR)" by IUCN. Its area of distribution is small and fragmented less than linear $5 \mathrm{~km}$. The Montseny Brook Newt is adapted to mountain streams and requires a pristine habitat, one which is currently being affected by conservation issues linked to climate change and human activities (logging, water catchments, visitor's frequency, among others). At the end of 2016, the Life Tritó del Montseny (LifeTM) project (LIFE15 NAT/ES/000757) was launched. This project's aim was to promote around fifty actions to ensure the conservation of $\mathrm{C}$. arnoldi and its natural habitat, in the Montseny SCI of the Natura 2000 Network, with five strategic lines: 1) To increase scientific and technical knowledge with regard to $C$. arnoldi conservation status and its habitat management. 2) To ensure its genetic conservation and expand its geographic distribution 3) To eliminate or minimize threats that exist in the riparian habitat. 4) To Involve and engage stakeholders and local residents in the conservation of Montseny brook newt riparian habitats. 5) To establish proper legal coverage and define long-term strategic planning. Since 2017, several actions linked to the strategic lines 1 and 3 have been initiated. Many unforeseen events have been overcome and there have been some failures, but there have also been several satisfactory results that allow us to be optimistic about the future of the species. These achievements and failures obtained throughout the process provide us with essential information to develop an adaptive habitat management. Dozens of monitoring surveys have been carried out which allow us to understand the evolution of natural populations, to improve our knowledge regarding their biology and to assess the impact of conservation actions. In relation to eliminating or minimizing threats to the newt's habitat, some of the actions that are being carried out are: a) Land acquisitions and land exchanges with different private properties. b) Land stewardship with two custody agreements being signed. c) Reduction of water withdrawal with nine water catchments and distribution being remodeled. e) Improvement of water treatments and storage by installing ecological wastewater treatment facilities. f) Ensure ecological connectivity and riparian forest restoration by removing twenty-two river connectivity barriers removed and executing twelve forestry and bioengineering interventions within the riverside habitat. With regard to analyzing the conservation status, management activities and scientific and technical knowledge, active long-term monitoring of the newt population and hydrological conditions has begun. Here we present an evaluation of the actions carried out to improve the habitat of this species, including the necessary considerations for them to be implemented correctly and to be successful in a natural area, which is under public-private management.
\end{abstract}

Key words: Calotriton arnoldi, Montseny Brook Newt, Habitat management, Life. 


\section{Introduction}

Human activities have left a strong footprint on the Earth's land surface for thousands of years and even more so in recent centuries, which has led to a significant impact on natural resources. One of the major environmental effects of land-cover changes worldwide is the alteration of the hydrological cycle, which directly affects the quantity and quality of freshwater supplies [1]. Water resources, usually scarce and unevenly distributed throughout the Mediterranean region, are highly vulnerable to Global Change. Water demand for human use is expected to increase in the future, while both climate and land-use changes are expected to decrease freshwater supplies. Vegetation regulates the transfer of water between the land surface and the atmosphere, through rainfall interception and evapotranspiration processes. [2] reported a decrease in streamflow discharge in several Spanish rivers over the period 1921-96 and suggested that this negative trend should be understood as being caused not only by climate variability and increased water consumption due to irrigation but also by increased evapotranspiration from vegetation recovery in the headwaters. As a result of the effects of forest vegetation on rainfall interception and increased evapotranspiration, the water yield usually increases when forests are transformed into systems with lower biomass and decreases after revegetation processes $[3,4]$.

The Montseny massif is in the Mediterranean region, located only $60 \mathrm{~km}$ from Barcelona (Spain). Due to its geographical location and height, the PNRBM is a space of great biodiversity, which is inhabited by many species of very diverse biogeographical origins and where a significant number of endemic species occurs. Because of its high biodiversity and rich natural patrimony, the Montseny massif was recognised as a Natural Space of Interest in 1928, Natural Park in 1977, Biosphere Reserve in 1978 and, as a LIC by D. Habitat from EU in 2007. Montseny has been the subject of many scientific studies and, at the same time, it is one of the most visited places around Barcelona for mountaineering and other leisure activities. It presents a great biodiversity in terms of both animal and plant life and it is hard to imagine that this highly visited and busy place surrounded by dense human populations is the home to the Montseny Brook Newt (Calotriton arnoldi). This salamandridae is the most important endemic species of the Montseny Massif and it is one of the two most threatened amphibians in Europe, along with the Greek island of Karpathos' endemic frog (Pelophylax cerigensis). The population of the Montseny Brook Newt does not surpass 1.500 adults, its area of distribution is small and fragmented, (less than 5 linear $\mathrm{km}$ streams)and it covers an area of less than $8 \mathrm{~km} 2$ in total and the current trend is towards population decline $[5,6]$. For these reasons, it is now listed by the IUCN Red List in the category of "Critically Endangered -CR-" [7].

The presence of the brook newt in the Montseny Massif was detected in 1981. [8] published the discovery of Calotriton arnoldi's first population in the Montseny based on Miquel García de Castro's observation, who was the son of the meteorologist at Turó de l'Home Meteorological Station. Its presence was detected in two streams and became the southern limit of the Pyrenean endemism Euproctus asper, because at that time these populations were identified as Pyrenean Brook Newt. Although the authors pointed out the morphological differences between the newts from the Montseny and the Pyrenean populations, it was thought that these particularities could only be taken into consideration at a subspecific level. After several years of ecological, morphological and genetic studies, [5] reached the populations of Euproctus asper in the Montseny massif and argued that a new specific level (Calotriton arnoldi), which suggested the change of genera to Calotriton following the systematic recommendations made by [9]. It was at that moment that the conservation status for the populations of Montseny Brook Newt from PNRBM changed due to the very few locations it could be found in while the scarcity of specimens, worryingly suggested that $C$. arnoldi could be a severely endangered species $[5,10,11]$.

C. arnoldi presents a fragmented distribution in two areas located on the Tordera river's eastern and western slopes (Figure 1). Both subpopulations are separated genetically and morphologically and recent studies estimated that this isolation occurred about 
60,000 years ago $[12,13]$. The distribution of the Montseny Brook Newt in the streams is also fragmented and discontinuous within each nucleus.

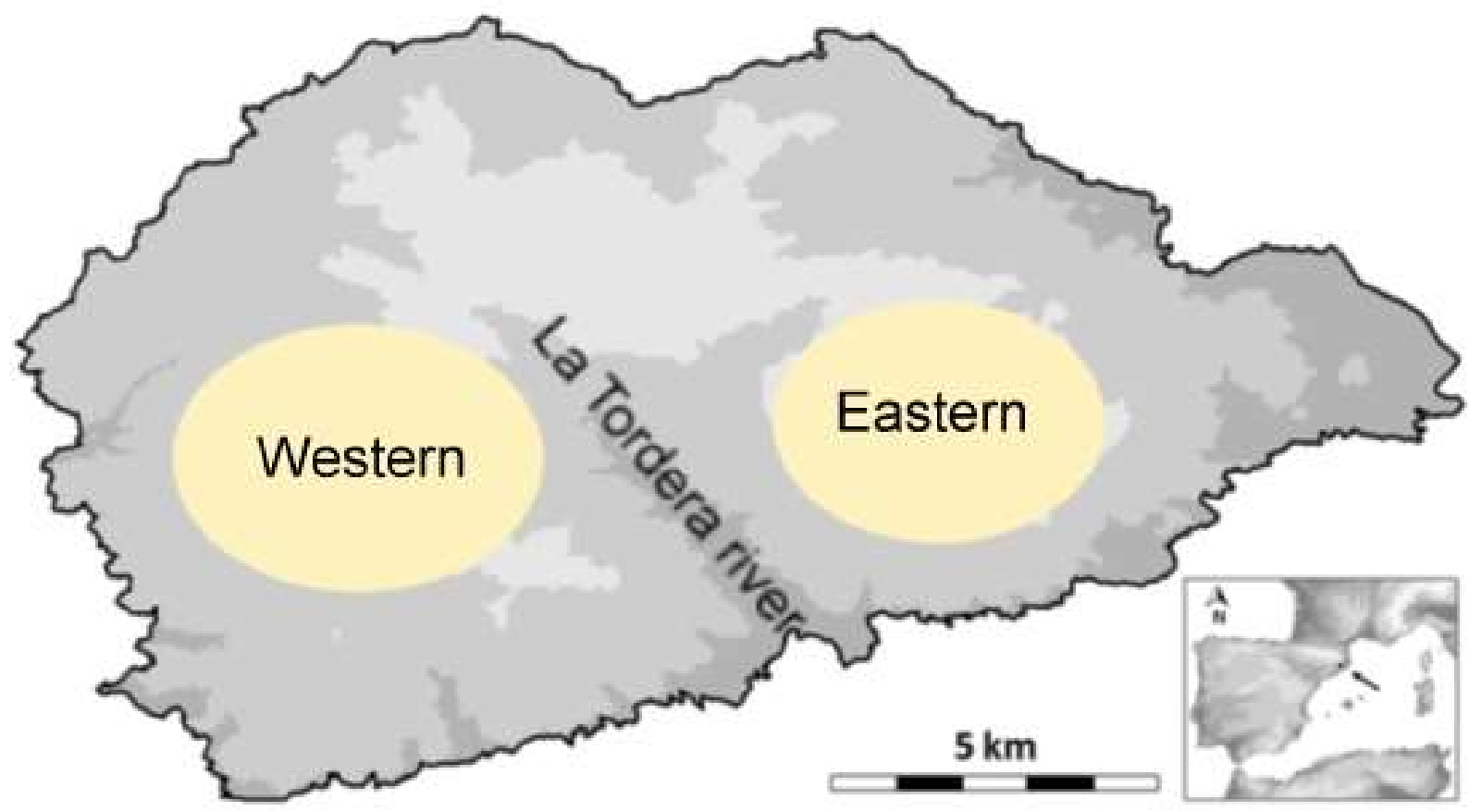

Figure 1. Localization of PNMRB and the two isolated subpopulations of C. arnoldi into La tordera river basin.

The Montseny brook newt is only found higher than $600 \mathrm{~m}$ above sea level in clean, cold and well-oxygenated streams with numerous falls and pools, surrounded by wellstructured beech and oak forests. It is a small newt as males measure $56-59 \mathrm{~mm}$ and females 57-59 $\mathrm{mm}$ in snout-vent length while the maximum total length is $103 \mathrm{~mm}$ [14]. The dorsum is dark, chocolate-colored and the head is heavily flattened (Figure 2). Body is oval-shaped in cross-section and has some dorsoventral compression [5]. Most aspects of C. arnoldi's life history are quite similar to its sister species, the Pyrenean Brook Newt (C. asper), but unlike the Pyrenean Brook Newt, in which immature specimens go through a terrestrial phase that can last up to two years, Montseny brook newts never leave the streams and are therefore aquatic throughout their life. This biological characteristic is very important in conservation terms because this newt's dispersal activity can only take place in an aquatic environment. On the other hand, the larval period lasts for more than a year and this forces them to live in streams that do not undergo drought periods, which in turn limits the distribution and dispersal area. This means that the Montseny newt can only inhabit streams with shales and highly fragmented and fissured rocks that allow the newts to access the underground aquifer during drought periods.

Since 2007, PNRBM has monitored C. arnoldi populations annually in order to evaluate their state of conservation and determine the distribution area. This research strategy allows PNRBM's technical office to have up-to-date information so that useful decisions are made with regard to species management. Once the PNRBM's Conservation Plan [15] was drawn up in 2011, managers were able to strengthen the monitoring program the Montseny Brook Newt and its habitat, the study of population genetics, performed population health surveys, increase and improve the breeding programme's functionality and release captive newts in previously uninhabited streams. Since 2013, Valbuena-Ureña and his collaborators $[12,13,16]$ have genetically analysed the state of the populations and highlighted the differences between the eastern and western populations, which has led 
to them being managed separately. For this reason, the Government of Catalonia (Generalitat de Catalunya) has started a separate captive breeding plan $[16,17]$ in order to preserve wild genetic variability..
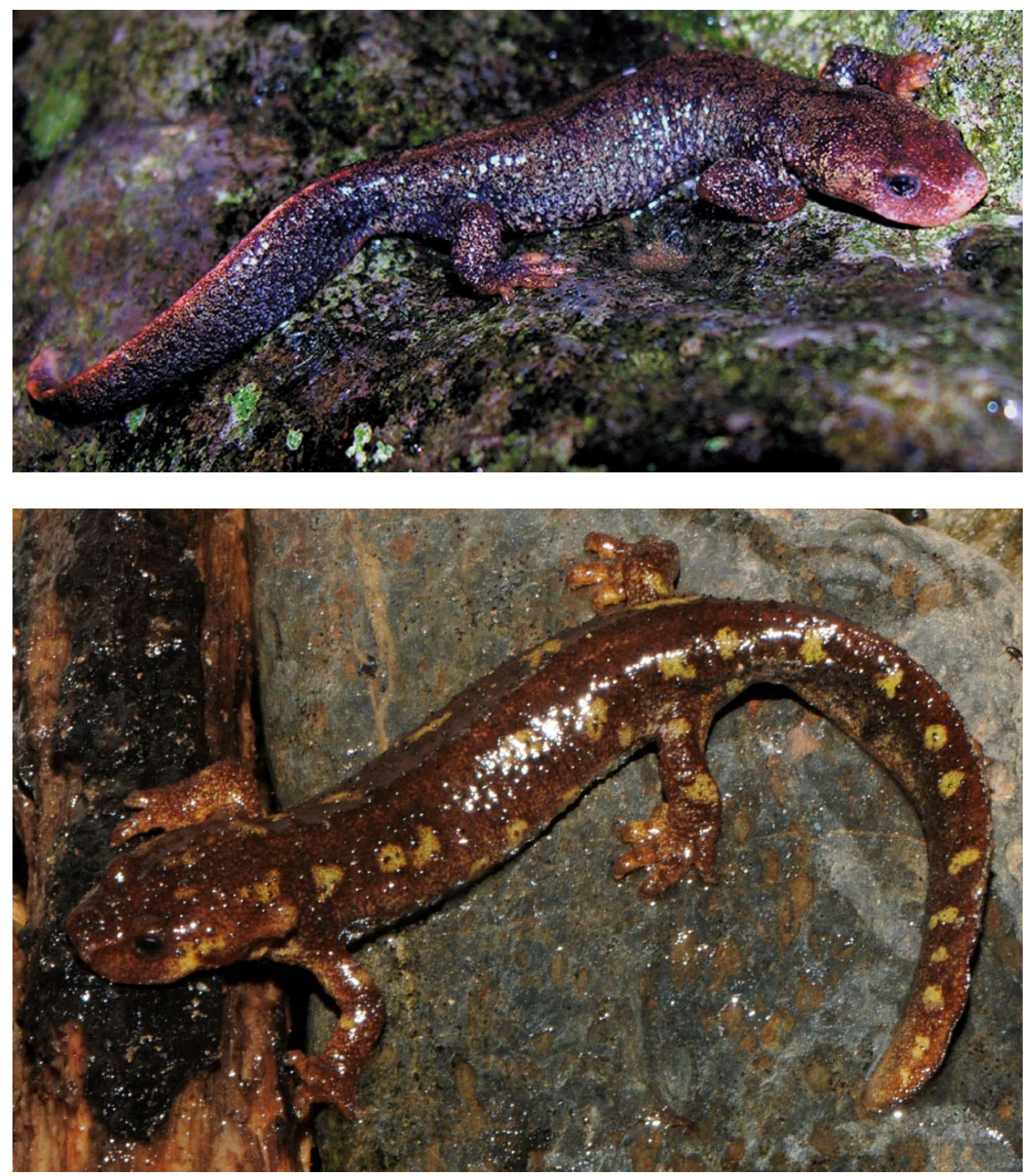

Figure 2. Adults of C. arnoldi. Above: Male of western subpopulation. Below: Male of eastern subpopulation.

Finally, in 2016, the Life Tritó del Montseny project (LifeTM from now on) (LIFE15 NAT / ES / 000757) began with Diputació de Barcelona (DiBa), Diputació de Girona (DiGi), Generalitat de Catalunya (GC), Zoo de Barcelona (BCNZoo) and Forestal Catalana S.A. $(\mathrm{FC})$ as partners in the project. It was born out of the need to protect this endemism listed by the IUCN as critically endangered and the fact that knowledge of the species and its 
habitat requirements were scarce. The LifeTM project provides the necessary tools for a suitable management of the habitat and the species and allows it to obtain the necessary data to plan for the future management of the populations and habitats of this highly threatened species. Despite PNRBM being a protected natural area, eighty percent of the territory is owned by private landlords, thus limiting the management of their populations. After previous experiences, several risk factors have been detected which, based on their causality, may be classified as i) anthropic, ii) ecologic and iii) management capacity.

i) As part of the first group, water catchments in streams are one of the most dramatic and immediate threats to this species. Large amounts of water are being extracted from PNRBM for human consumption and livestock along all the river secondary basins. It is likely that water overexploitation is a severe threat because of the species' ecological requirements [5]. Moreover, the fact that the current environmental legislation is not enforced efficiently with regard to the maintenance of ecological flows and their monitoring constitutes a significant difficulty when dealing with this threat [18]. Another cause behind water flow reduction in the La Tordera basin could be the presence of forest plantations and more specifically those that consist of fast-growing allochthonous conifers. They require large amounts of water and take up 11,40 ha within the natural range of $C$. arnoldi, which is $12 \%$ of the secondary basins' forest area and where the species live [19]. Thus, the disappearance of the autochthonous riparian forest and the fact it has been replaced by species that are more economically profitable has also increased the hydric stress. Traditional forest exploitation practices such as logging of riparian forest, the use of the steam bed for wooden log/trunk transportation, stretches of the stream being buried by creating forest tracks or stream erosion in places where the wooden logs/trunks were placed have had significant negative impacts.

ii) It may also be the case that global warming is affecting the species. For instance, the beech (Fagus sylvatica) forest, an excellent habitat for C. arnoldi, has shifted upwards by $70 \mathrm{~m}$ at the highest altitudes $(1,600-1,700 \mathrm{~m}$ asl) since 1945 , and is being replaced by holm oak (Quercus ilex) forest at lower altitudes (800-1,400 m) [20]. Consequently, the species most favourable woodland habitat is moving up into areas where the streams are drying out more. In the short-term, all these threats result in an absence of stream connectivity and a reduction in available habitats.

iii) On the other hand, the PNRBM is one of the most frequented leisure areas because of its proximity to dense urban areas (i.e. Barcelona) which causes a high number of human-environmental interactions, including poaching. The recent appearance in Europe of emerging amphibian diseases associated with the genera Batrachochrytium forces us to be very strict with regard to preventive biosecurity measures, since an isolated focus of $B$. salamandrivorans has been detected very close to the $C$. arnoldi populations. Based on experimental evidence, this pathogen has been shown to be lethal for the Montseny Brook Newt [21,22]. Methodological difficulties, the strengths of the LifeTM project due to the species ecology or biology and its current conservation status were very significant factors prior to the start of the LifeTM project, the aim of which is to ensure the future survival of the species.

The goals proposed by the Life TM project are: 1 . To increase scientific and technical knowledge linked to C. arnoldi conservation status and its habitat management. 2 . To ensure its genetic conservation and expand its geographic distribution. 3. To involve and engage stakeholders in the conservation of Montseny Brook Newt's riparian habitats. 4. To eliminate or minimize threats that exist in the riparian habitat. 5. To establish proper legal coverage and define long-term strategic planning.

Despite the project having 5 critical operative objectives and their respective actions, the present article aims to present the actions that have been carried out to restore the shore habitat and the evolution of $C$. arnoldi natural populations in recent years. Therefore, the aim of this study is to present and analyse the actions and goals reached by the LifeTM in relation to habitat and species management. It also aims to indicate which actions have been the most effective when taking into account the intended objectives. The implemented actions tend to minimize the current threats to the Montseny brook newt and lead 
to an improvement in their conservation status. These results are presented and discussed. Finally, we hypothesize about the future conservation actions and work needed in the post-Life project in order to improve the habitat and therefore maintain and increase the population and distribution levels.

\section{Materials and Methods}

2.1. Increasing scientific and technical knowledge to C. arnoldi and conservation status.

Due to the scarcity of information on the biology, ecology and demography of this species, the Life TM project included the monitoring and surveillance of the Montseny Brook Newt populations as one of the project's fundamental elements (Action D2: http://lifetritomontseny.eu). The development of this action includes, among others, the following specific tasks: a) Monitoring of the species' wild populations throughout their geographic area in the PNRBM. b) Creation of new population by releasing newts which were born in breeding centres [23,16]. c) Monitoring these new populations. The final goals of these actions were to improve $C$. arnoldi conservation status based on a better understanding of their ecological and biological requirements that would enable the development of the best actions for habitat and species management and help to establish new populations in the potential area of distribution [24,25].

There is a need for greater knowledge of ecological parameters such as the accurate distribution, demography, migration rates, activity and the phenology, among others. These parameters, which are based on the analyses of biotic and abiotic variables of habitats where C. arnoldi is present and absent within the potential distribution area, will allow us to reveal which habitat characteristics, at the present time, are related to the distribution and abundance of the newts. There are many practical implications resulting from the knowledge produced by interpreting this information. One of them is to have an annually updated diagnosis regarding the status of the species for each population and any changes in their distribution. Another practical implication is to determine the causes of local declines, applying the corrective measures on the habitat, and potentially, to release captive-born newts in order to bolster the populations providing the causes behind the decline are clearly identified and reverted. The data obtained on population demography regarding the habitat characteristics may be very useful. For example, this can determine the streams where C. arnoldi is absent and, in terms of potential geographic distribution, which have optimal habitat characteristics so that new populations may be created with newts from the captive breeding program $[23,16]$. Each stream's toponymic name and coordinates have been omitted in all presentations and papers, in order to protect the species. Population codes are used to designate the streams where C. arnoldi present wild or introduced populations.

\subsection{Stream habitat and hydrology}

Since the beginning of the Life project, the location, installation and monitoring of sensors with automatic data storage have been planned in several of the PNRBM's streams. At the same time, meteorological stations have been installed to correlate the data obtained by the different sensors. Two types of sensors have been used to continuously track two of the torrents' parameters: temperature sensors and water level sensors to measure their flow. The latter requires it to be calibrated with a series of real flow rates. Flow measurements were carried out using the dilution technique. Currently, park rangers and technicians carry out most of these tasks, and a long-term hydrological monitoring network is now in place. This monitoring programme is a surface water hydrological monitoring network implemented to provide a time series of quantitative (i) and qualitative (ii) hydrological data. It has been established and started by means of two actions: i) Continuous monitoring of the brooks' discharge, light and temperature through sensors with automatic data loggers and the installation of meteorological stations to collect data 
on a regular basis. This network currently includes: 5 meteorological stations, 7 water level sensors (measure stream flow) and 15 light and temperature sensors (Figure 3). And last year, the area's only historical hydrological and meteorological data series (a data series spanning 30 years) was also integrated into the network (Anna Avila-CREAF- 1983-2019, own and unpublished data.).

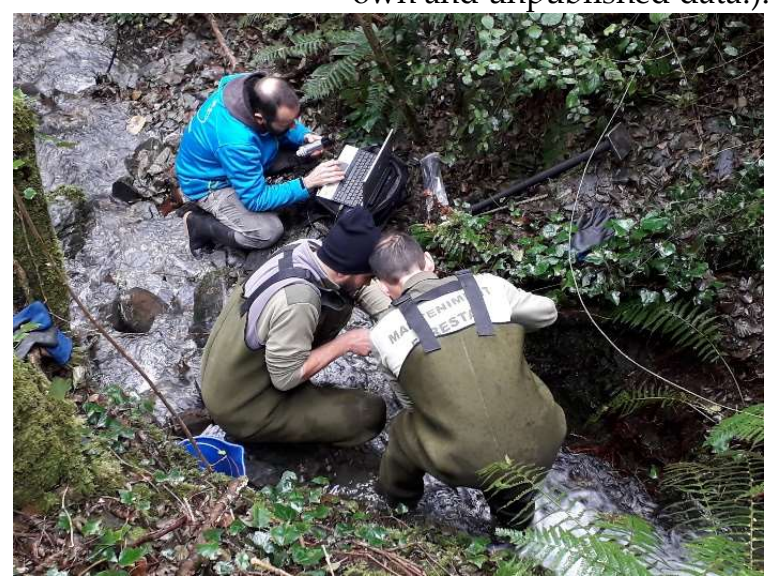

(a)

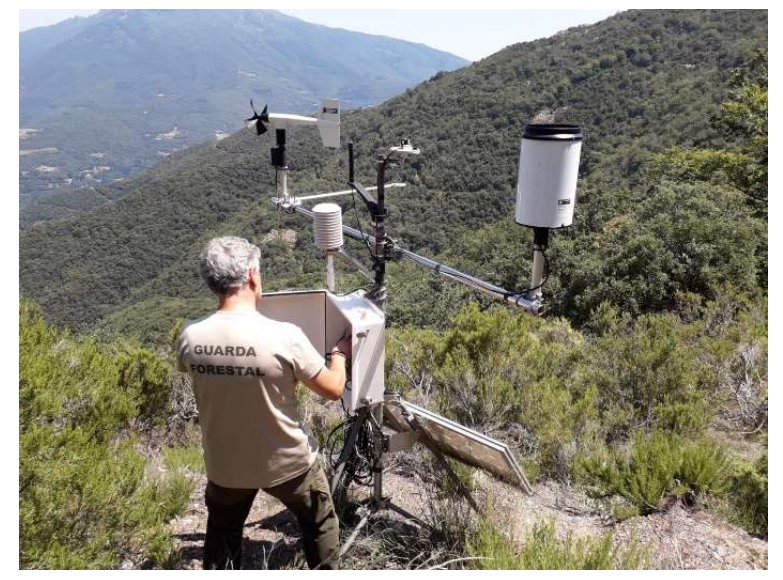

(b)

Figure 3. Network of monitoring abiotic variables. (a) Technicians downloading hydrological data. (b) Meteorological station located in eastern subpopulation area.

ii) Monitoring Aquatic State of the studied stretches by undergoing periodic visits that follow a specifically designed Protocol of LifeTRivers (http://www.lifetrivers.eu). Description of the hydrological state shows whether the waterflow has been interrupted, if ponds are present and their actual dimensions as well as whether the stream has completely dried up. To this end, a plan has been designed to monitor the hydrological status of 12 streams through periodic visits in which different parameters are monitored to determine their status. The frequency of these visits increases during periods of low rainfall, such as late spring, summer and late winter.

The Montseny Brook newt hydromorphological habitat has been described. Neighbouring and similar mountain brooks without newt populations have been classified as well, with the aim of finding possible newt-excluding hydromorphological factors. The data was obtained from a two-season sampling (late spring and late summer 2017) of a set of 7 streams where the newt lives as well as from 5 streams of similar characteristics with catchments where the newt has never been found. Stretches of 30 metres were established in each brook to perform the hydrological description [26,27].

In June 2018, a massive campaign was carried out to collect water samples from the Montseny brooks to analyse the water's chemical components. A total of 72 sites were visited, 59 samples were obtained and 13 chemical parameters were analyzed: $\mathrm{pH}, \mathrm{H}^{+}$, alkalinity, $\mathrm{Na}^{+}, \mathrm{K}^{+}, \mathrm{Ca}^{+2}, \mathrm{Mg}^{+2}, \mathrm{NH}^{4+}, \mathrm{NO}_{3}{ }^{-}, \mathrm{SO}_{4}^{-2}, \mathrm{Cl}^{-}, \mathrm{Cu}$ and conductivity) following the protocols of the CREAF laboratory (Avila, 1996). Of these samples, 40 belonged to stream sections where the newt has not been detected, and 19 to sections where it is present [28,29].

In 2019, a geomorphologic, geotectonic and hydromorfphologic study on the river courses where it is located compared to where $C$. arnoldi is not present was conducted to outline the parameters that define the fluvial habitat of the newt, and, to identify if there is any geological or geomorphological factor that conditions its absence where it is not present. Sixteen streams of the upper La Tordera basin have been analyzed while in each river course there have been 1, 2 or 3 control stations, resulting in a total of 29 sections of ten meters of length [30]. 


\subsection{Monitoring of wild populations}

\subsubsection{Previous experiences}

After the species description in 2005, monitoring of natural populations started in order to collect useful information to evaluate $C$. arnoldi state of conservation. Because of the difficulties in accessing most of the distribution area, the surveys were performed during the period 2010-2015, at night and only counting the number of newts in a short section and in seven of the eight streams. From 2016 onwards and up to the present day, the sampling covered most of the stream sections inhabited by the species with the exception of three of them, where the stepped orography precluded moving easily along them. During this period, sampling of wild populations was performed by one of the main researchers with the help of two rural agents who joined from the GC's mountain operations group. At the same time, a study was carried out (one for each subpopulation) by using the capture-recapture method and this was performed on two model natural populations so as to develop the knowledge regarding the species demography.

Newts were caught manually in a short section (less than $150 \mathrm{~m}$ ) in spring and autumn and at nighttime, during the period 2006-2009. The number of nights spent varied for each season, year and population. The results obtained provided valuable information on demographic parameters such as population size and survivorship. Other pieces of research have been carried out to increase the knowledge on the species biology and the populations' state of conservation. I.e. studied the morphological and mitochondrial differentiation between the two subpopulations $[12,16,5]$ in greater depth. Additionally, a monitoring protocol for infectious diseases has been launched which entails regularly sampling natural populations during the usual monitoring process. During this period and before the implementation of the LifeTM, we made significant progress in species conservation by launching a program for the creation of new populations. This program was based on two concrete actions. Firstly, we chose several streams where, after many searches, the species had not previously been found and therefore where it could reliably be assumed it was not present. Sampling to search favourable placements of new populations greatly benefited from the financial support provided by the Bin Zayed Species Foundation. The second action involved the improvement and increase in the production of captive-born newts by opening two new centres for species reproduction (Wildlife Recovery Center of Pont de Suert (CRPS) and BCNZoo).

During the LifeTM project (2017-2021), the exhaustive monitoring of all known populations using capture-recapture surveys was an unaffordable objective because of the economic cost and monitoring effort level needed. In order to maximize the amount of information and minimize the costs, three kinds of surveys were designed (intensive, extensive and new population surveys) to gather ecological data of all known populations. For each type, monitoring populations were created by implementing a specific field methodology designed to achieve different goals. In order to avoid the spread of emerging infectious diseases, especially chytridiomycosis, biosecurity protocols were implemented [31-33] throughout the sampling. During the surveying, the field material and boots were disinfected using Virkon S, before and after visiting each population, while nitrile gloves were used when newts were manipulated.

The methodology used during field surveys greatly depends on the species' ecology and their particularities. Montseny Brook Newt is completely dependent on water throughout its entire life cycle. Unlike its congeneric brook newt $C$. asper, C. arnoldi never leaves the water in any of the age classes: larvae, metamorphics, juveniles, subadults and adults live in the water at all times. This behavior is different to the sister species (C. asper), in which some immature specimens live on land, from metamorphosis until sexual maturity [34]. It is essential to understand C. arnoldi low dispersal rate and to determine which demographic models should be used. The surveying prior to the long-term moni- 
toring project for Montseny Brook Newt populations had already provided valuable information on some aspects of their life cycle. They evidenced that the species is almost exclusively active at night. This species has a fossorial lifestyle and it spends most of its time hidden under rocks on the stream bed and observable activity only takes place only there is surface water. Consequently, field monitoring and sampling must be performed at night when activity is high, taking into account the proposed objectives, the species phenology, its habitat and the accessibility for the research team.

\subsubsection{Intensive survey}

Intensive surveys require a large monitoring effort because we want to obtain the maximum amount of data regarding ecological and demographic parameters for C. arnoldi. In the chosen stream, a $150 \mathrm{~m}$ stretch was selected and divided into sections of $10 \mathrm{~m}$ each. Intensive surveys were performed from 2018 to 2021. The stream was regularly surveyed on a monthly basis and by moving upwards, to prevent the cloudiness of the water, which would make it difficult to determine the specimen's location. In the selected stretch, newts were actively searched (i.e., removing rocks) and caught manually (gloves were used as protection). Newts were marked by injecting a visible implant elastomer (VIE, Northwest Marine Technology, Inc.) and by using a visual code based on ten injection points: four in the abdomen, four in the legs and two in gular region [35] while a combination of colours were used to code males and females. (Figure 4).

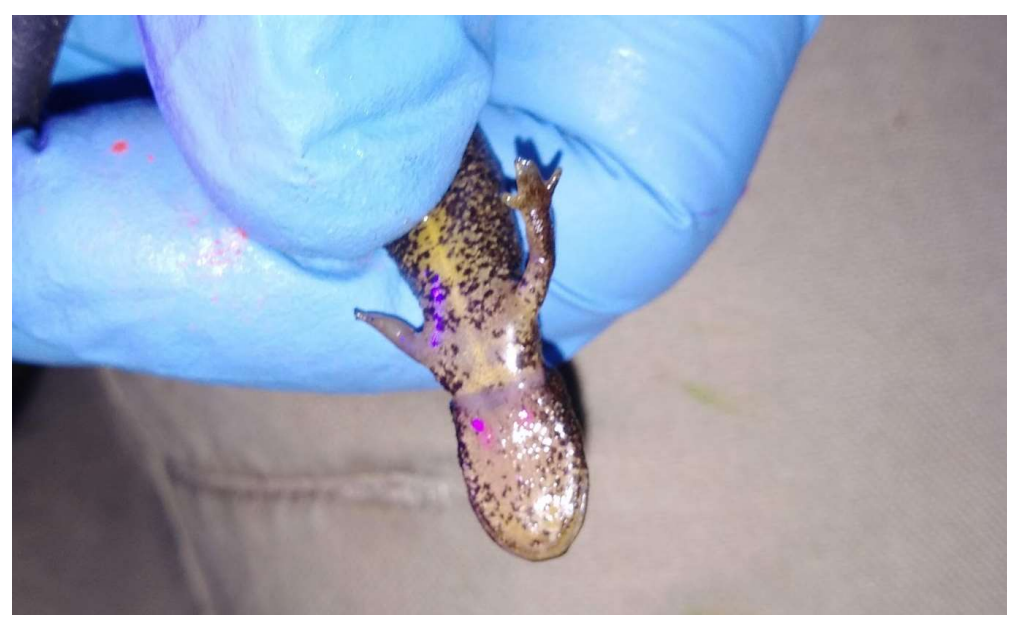

Figure 4. Marked individual with elastomer in gular area.

Captured individuals were georeferenced, measured (snout-vent and tail lengths), sexed by assessing the sexual shape dimorphism [14] or assigned to one of three immature age-classes considered (larvae, metamorphic, juvenile and subadult). The sex ratio was calculated as the proportion of mature males in relation to the total number of adults [36]. Immature individuals were not included in estimated population size models. To estimate population size we assumed that populations were closed on a yearly basis. This assumption is based on the fact that mortality during the relatively short sampling period can be considered negligible, as Calotriton newts are not particularly mobile organisms $(34,37,38)$ and the selected stretch includes the upper limit for the presence of water and the lower limit for the presence of the species in this stream.

The intensive survey has also made it possible to estimate the basic demographic and ecological parameters and to know the population dynamics through time and perform population viability analyses. These parameters (survival rates, mortality, growth, migration and recruitment, sex-ratio, sexual maturity, annual patterns of activity, among others), have been used to estimate the carrying capacities of the torrents and this determines 
the number of specimens that we need release for the creation of new populations with high probability of success. Obviously, there are too many stochastic or factors which cannot be controlled, which in turn can modify the released models, but it will be commented on above.

\subsubsection{Extensive survey}

Wild populations of the species are currently known to inhabit eight streams, three in the eastern area and five in the western one, while $75 \%$ of the riparian habitat in watersheds with wild newt populations are found on private properties. Following the methodology used from 2016 onwards, field surveys were carried out which covered almost all of the streams known to be naturally inhabited by the species, apart from excluding three short and stepped stretches that cannot be sampled safely. There was preference for samplings to be performed during spring, mainly because during this season, there was enough surface water flow, but due to droughts and logistic limitations, there were some years in which these were carried out in autumn.

During the samplings, we searched for newts that were active in the stream's rocky bed surface while trying to prevent any alteration to the species microhabitat. No active searching by removing rocks was performed and only specimens which were detected visually were considered. We tried to observe the maximum number of individuals, but avoided catching them and georeferenced all the observations. Newts were sexed when possible and this was based on their body shape, which is markedly dimorphic in this species [14]. Small individuals that clearly have a snout-vent length of less than $5 \mathrm{~cm}$ were considered immature specimens. Thus, we have considered three individual classes: adults (males and females), juveniles and larvae. In order to achieve comparable data in all of the species' populations, this type of surveying was also used in the torrent A2, where additional intensive surveys took place.

We summarized the gathered information by computing three statistics: percentage of stream length inhabited by newts, relative adult abundance (number of adults/stream length) and connectivity calculated by modifying a dendritic index.

\subsubsection{New populations habitat selection}

Because of the species critical situation shortly after their description in 2007, a captive stock of newts was funded by placing 20 newts from the two subpopulations in the facilities of the Wildlife Center Recovery of Torreferrusa (Government of Catalonia). Captive breeding is one of the most effective ways to keep a genetic reserve of such critically endangered species, but it is also a tool to attempt to expand its range by reintroducing it into potentially suitable habitats. The breeding facilities were designed to keep individuals separate from each subpopulation in a specific aquarium system and to avoid interbreeding among them, after which they were placed in a small-refrigerated house. [39]. The results of this experience were positive and it led to the reproduction of adults in both subpopulations in 2017. During the development of this centre, breeding technicians acquired a lot of expertise on the reproduction, growth and alimentation of captive C. arnoldi but several issues arose during this process. The most important of these were the high mortality of larvae during the first weeks and the remarkable differences on fecundity between pairs. In order to try to resolve this, the LifeTM project has promoted the extension of breeding centers and it has included research on the population's fecundity, diet and demography as well as experimental improvements on the environmental conditions [39].

\subsubsection{Selection of new population habitats}

Prior to and throughout the LifeTM project, brooks were monitored and originally, the objective was to determine which streams harbored populations of $\mathrm{C}$. arnoldi. Once it 
was determined where the newt was actually absent, the species' potential distribution area was estimated by using Models developed that employ the maximum entropy statistical method implemented in Maxent software $[40,41]$. The lack of biological and environmental representativeness in the available data has also been taken into account when calibrating the models [42]. One of the most important results of the analyses carried out on C. arnoldi potential distribution was the contrast between the existing environmental data, which was imprecise, and the small area of distribution $(8 \mathrm{~km} 2)$. In this case, the predictive tools and the environmental data available are clearly insufficient and the first time that the potential distribution area was estimated was not very precise. To solve this issue, LifeTM decided to create a multidisciplinary expert committee, which provides more accurate data from La Tordera river basin and which was obtained from local studies and field surveys. The reports and references provided by this committee give a more precise potential area of distribution for the species (Figure 5).

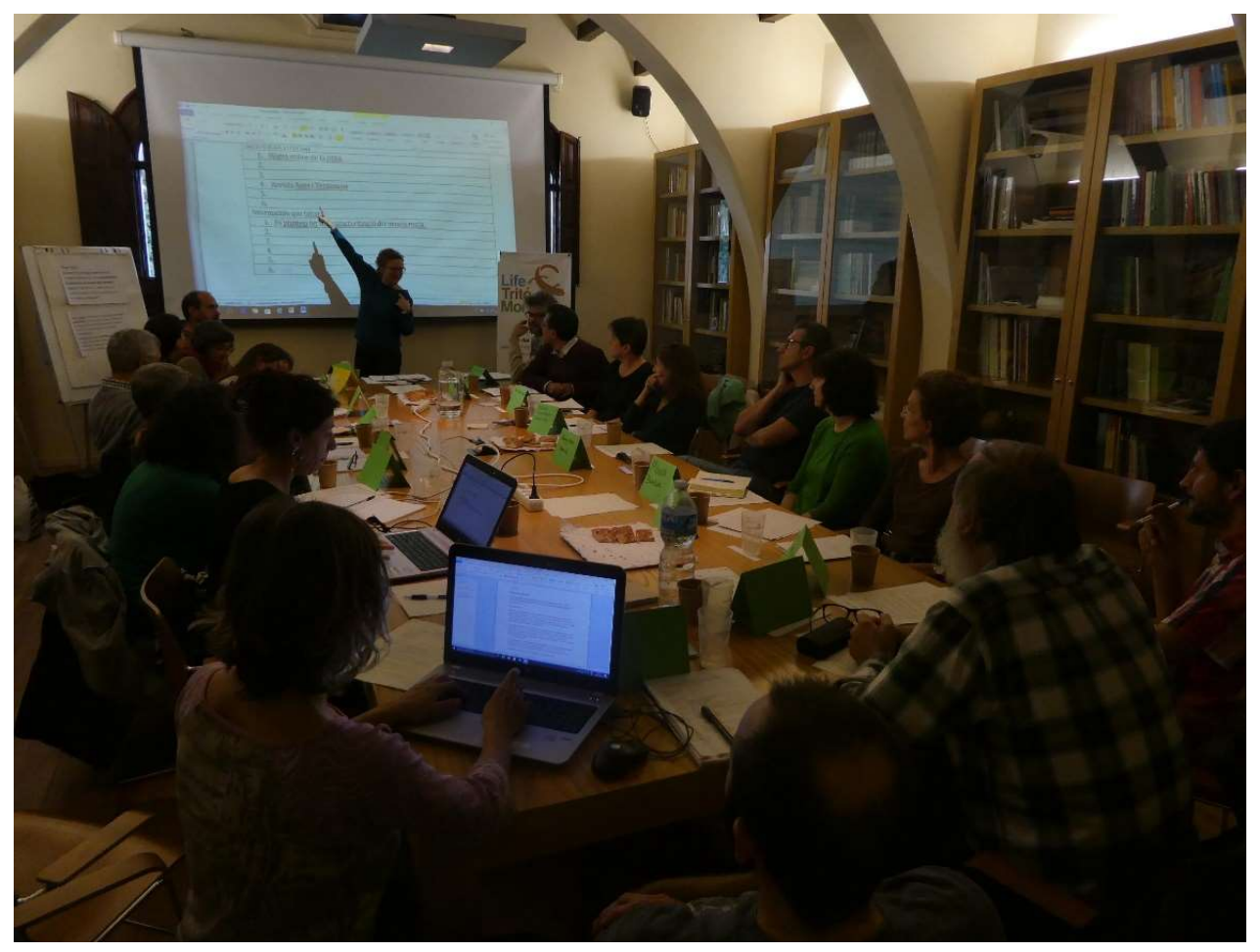

Figure 5. Hydrologist committee workshop of the in the PNRBM's Information Center (Masia Mariona, Mosqueroles, Barcelona).

Comparative multidisciplinary studies began between the streams which the newt inhabits and those that it does not. Plant structure, hydrology, trophic availability, geomorphology and the presence of predators, among others, were analyzed [26,27,43,30,44]. In order to jointly analyses the results obtained by different disciplines, a New Populations Analyses Commission was created and it worked in parallel with the experts commission to decide, after several field surveys in optimal candidate streams, how, where and when to release them as well as the number and what age classes should be released. In order to determine this, [45] we estimated the temporality, the stream's load capacity and predicted the demographic evolution of newly released populations based on biological and ecological data obtained in the field surveys. The anthropic activities in the first selection streams were also taken into consideration. 
A cost evaluation is also important to determine the project's effort capacity and the viability of its objectives. These two committees have proven to be very useful for decision-making processes and, for the time being, very effective given the results obtained.

\subsubsection{New populations surveys}

New population surveys require a similar monitoring methodology because an estimate of ecological and demographic parameters of C. arnoldi new population will help us establish if our prediction on the evolution of demographic parameters fits the data we obtain in wild populations. The analyses of the temporal evolution of the newly established populations and the selection of the habitat after their release provide us new data on the species' needs. Before the LifeTM project, experimental releases were made in 2010, 2011 and 2014, they was reinforced in some cases (Table 1). All of the newts released were made from specimens in breeding centers. Before their release, newts were previously sexed, measured, weighted and marked using Trovan microchips. Release points have been marked with iron flags that have a specific reference marking code MNYMI00 (park code -3 digits-, locality -2 digits-, order number -2 digits) while GPS coordinates for each point have been registered. Once the specimens were released, two surveys per year were carried out, which entailed active searches of specimens along the entire marked stretch and these were extended to a few meters downstream and upstream, from the lower and upper points respectively. The main goals are to analyze movement patterns, check for differences in body condition and follow the temporal evolution of the population dynamics.

Table 1. New populations established in the C. arnoldi potential area of distribution. Only population codes are written because of conservation policies for this CR species. Range: slope location in La Tordera river basin. First release: year when first release was made. Last released: last booster. Last recapture: year when C. arnoldi was captured in the stream. Property: Land property where the new population and stream stretch are located.

\begin{tabular}{ccccccc}
\hline Code & Range & $\begin{array}{c}\text { Number of } \\
\text { released newts }\end{array}$ & $\begin{array}{c}\text { First } \\
\text { released }\end{array}$ & $\begin{array}{c}\text { Last } \\
\text { released }\end{array}$ & $\begin{array}{c}\text { Last } \\
\text { recapture }\end{array}$ & Property \\
\hline A4 & Eastern & 166 & 2011 & 2014 & 2016 & Private \\
A5 & Eastern & 63 & 2020 & 2020 & 2020 & Public \\
A6 & Eastern & 127 & 2014 & 2020 & 2021 & Public \\
B6 & Western & 436 & 2010 & 2020 & 2021 & Private \\
B7 & Western & 106 & 2014 & 2015 & 2019 & Private \\
B8 & Western & 261 & 2019 & 2021 & 2021 & Public \\
B9 & Western & 267 & 2021 & 2021 & --- & Public \\
\hline
\end{tabular}

\subsubsection{Biosecurity measures}

To control and monitor emerging diseases affecting amphibians and the Montseny brook newt, we decided to create a biosecurity commission with three main purposes. i) establishing the protocols to be followed in all activities carried out in the PNRBM [31-33] in order to minimize the risk of introducing an emerging disease into the species' habitat (educational, economic, sports, leisure, ...). ii) setting up space and time monitoring processes to determine the presence or absence of pathogens in the species' habitat as well as a security perimeter and, iii) training PNRBM workers and raising users' awareness of biosecurity protocols (Figure 6) to be followed in all environmental activities within the relevant area. 

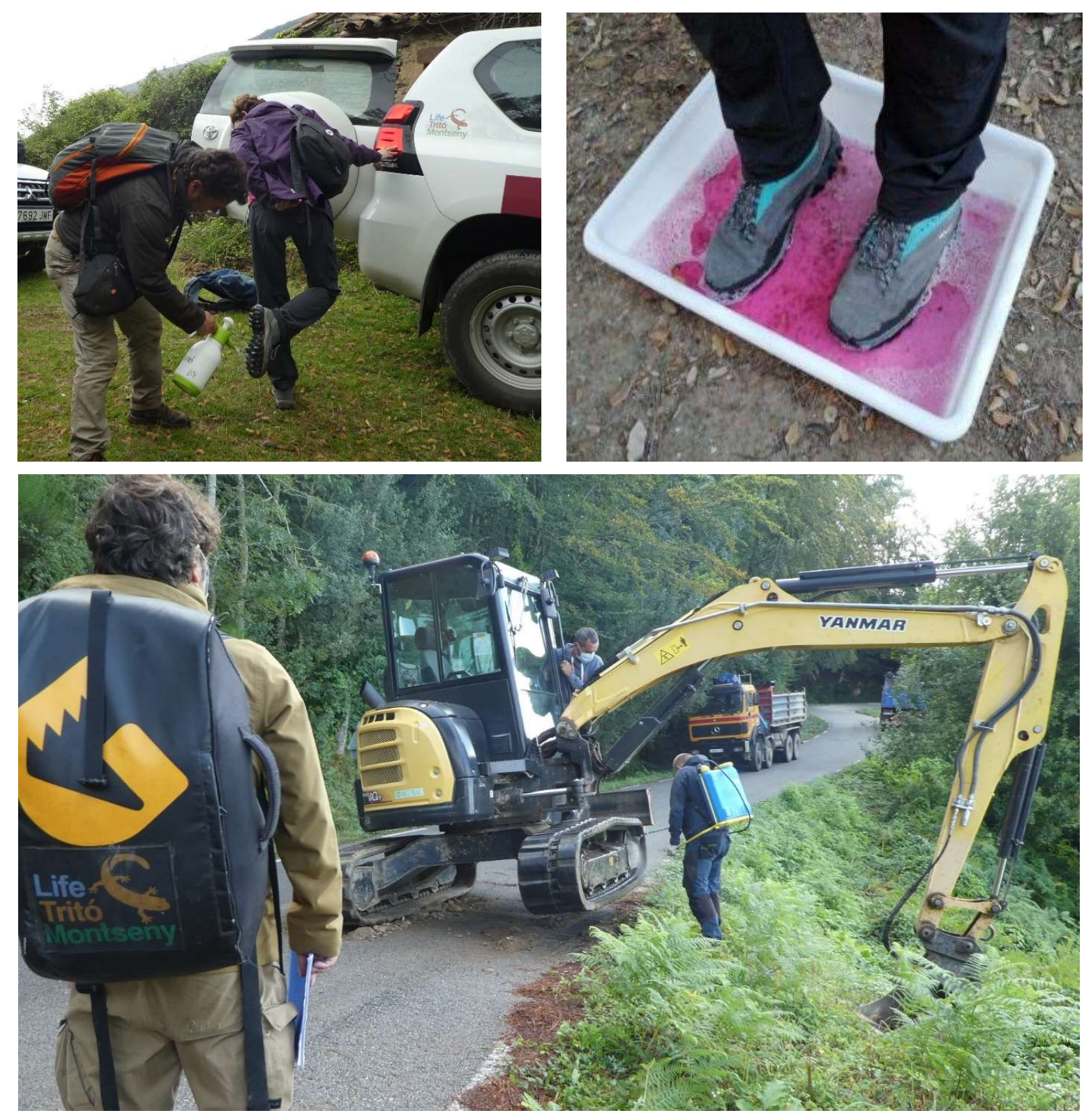

Figure 6. Biosecurity procedures to prevent entry of pathogens in C. arnoldi distribution area. The disinfection of all material and machinery with Virkon ${ }^{\mathrm{S}}$ is mandatory before and after all the activities.

\subsection{To involve and engage stakeholders}

\subsubsection{Dissemination}

Many of the actions linked to the preservation of the species are directly related to the use of the natural resources in the estates within the PNRBM. Only $20 \%$ of the surface area of this natural area is under public ownership. Due to this fact, the involvement of the local population has been a key aspect for the survival of the species.

Meetings have been promoted with forest owners to reach agreements between both parties. The aim has been to minimize the negative impacts on the species' habitat and to encourage the signing of land stewardship agreements. In addition to disseminating the project to the property owners within in the area, LifeTM has deployed different actions aimed at the general public. Due to the critical situation, the species finds itself in, the LifeTM Communication Commission and all its entities involved have agreed to maintain 
a common criterion, with regard to the news appearing in the media and in the different means of dissemination.

In the digital sphere, a website (https://lifetritomontseny.eu/), specific to the project, has been developed in three languages: Catalan, Spanish and English. Regarding social networks, the project has created Youtube and Twitter channels that can be accessed via the project's website.

\subsubsection{Education}

A travelling exhibition has been created with the title: "My name is Calotriton and I only live in Montseny". It consists of eight panels and a hyper-realistic model of the Montseny newt on a scale of 10:1. It shows different aspects of the species' biology and ecology, as well as the actions developed within the LifeTM project to improve its critical state of conservation (Figure 7). The educational programme "El Montseny a l'Escola" (http://www.elmontsenyalescola.cat) presents support materials on the Montseny newt for the educational community. It is aimed at primary school children with the objective of learning about the Montseny newt and the problems and conflicts associated with the water cycle. BCNZoo also offers an educational programme on the Montseny newt. School groups can visit the educational stand which was inaugurated in June 2018. There are also information panels and a documentary about the project which can be seen there.

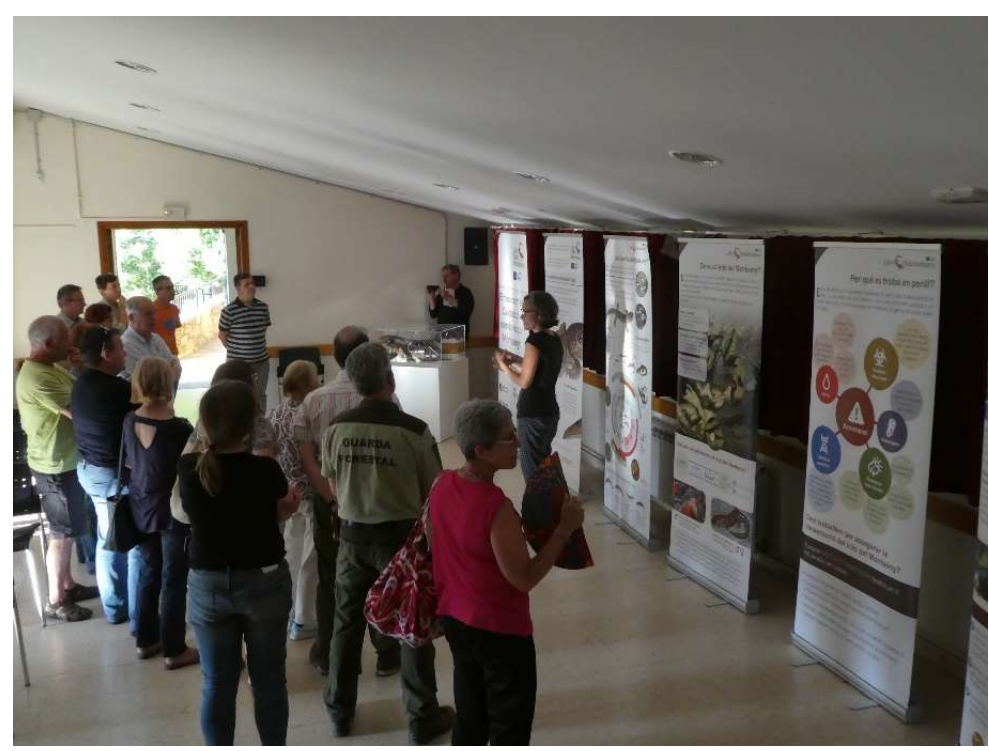

Figure 7. Travelling exhibition on C. arnoldi, its characteristics and its conservation threats.

\subsubsection{Involvement of local landowners}

The involvement of landowners has been achieved through plenary meetings. In these meetings, the project has been presented and involvement has been promoted in certain actions that are directly related to the use of natural resources on the farms (such as water and wood). The mechanisms to involve landowners have resulted in the signing of land stewardship, purchase or exchange of land contracts and agreements.

\subsubsection{Technical and scientific implications}

The presentations made at technical and informative congresses have contributed to disseminate the project locally, nationally and internationally. The involvement of the scientific and technical community has also been sought through thematic participatory 
meetings (experts in hydrology, experts in introduction-breeding and experts in education, among others). The aim has been to gather opinions, reach a consensus on actions and involve these groups in specific projects linked to LifeTM main objectives.

\subsection{To establish proper legal coverage and define long-term strategic planning.}

The Montseny Brook Newt was included in Annex IV of the Habitat Directive as a Euproctus asper, although they have another scientific genus, which classified them as a different species in 2005 (Calotriton asper, Calotriton arnoldi). One of LifeTM objective is to pursue the explicit recognition of this endemism in the Habitat Directive (92/43/CEE), in order to have greater legal cover to ensure its habitat conservation and to promote actions to improve its conservation status. Six conference days have taken place in the last two years (and in which two dozen experts took part) to plan for the future management of C. arnoldi and to agree on the Recovery Plan. The Montseny brook newt is found in the PNRBM, but they are not within special protection areas with management and operating restrictions. Therefore, it's necessary to restrict human activities inside its real and potential distribution area.

\subsection{To eliminate or minimize threats in riparian habitat.}

Prior to the launch of the Life project, the PNRBM [15] Conservation Plan analyzed the main threats from a conservation point of view, suggesting specific actions in order to reduce negative impacts on the species. Prior to 2016 and during the last four years, surveys carried out by PNRBM rangers allowed them to locate each of these threats to C. arnoldi. We used this information to schedule habitat restoration actions, which have been carried out as part of the LifeTM project. Most of the actions identified are being implemented according to their priority, the opportunity for them to be carried out and the availability of resources. In order to do this, an alphanumeric code was assigned to each action (type, number and property), located on the map while an execution project was drafted by the operations director, an administrative dossier was processed and finally, it was awarded to a suitable company. The procedure for the execution of the works included the implementation of the biosecurity protocol (Figure 6) and its regular surveillance by the operations director and herpetologist, so as to ensure the action is completed and if necessary, to propose modifications to the project. These surveys will be performed up to four years after the completion date in order to evaluate their efficiency and resolve any issues that may arise. We grouped habitat restoration actions by using five typologies according to their purpose and these include: 1) To reduce water catchments placed in the streams which the species inhabits by controlling and improving them. 2) To clean waste water by installing a water treatment plant that consists of ponds with hydrophytic vegetation. 3) To seize water rain by employing the catchment and conduction of runoff waters, filtering it and storing it in tanks so that it can pumped and used for gardening purposes, to fill swimming pools and for livestock. 4) To increase ecological connectivity by removing forest tracks or building bridges specifically designed to prevent the stream bed from being altered. 5) To restore the riparian forest by removing old conifer plantations, carrying out slope stabilization and promoting the replanting of autochthonous species.

\section{Results}

\subsection{Increasing scientific and technical knowledge to C. arnoldi and conservation status}

\subsubsection{Hydrological monitoring network}

During this period, the long-term monitoring of hydrological variables with regard to the Montseny brooks has been successful. There has been available information on temperature and flow discharge, along with the aquatic state, for three years. Currently, this 
network is fully operational and the first results have been published [44]. The first important results show the brooks with newt populations have not completely dried out despite summer hydric stress. The pools and a little surface flow (less than 0,5L/s) remain, even in the streams with the lowest discharge. Large variations in discharge have been recorded, from $0,5 \mathrm{l} / \mathrm{s}$ to $10 \mathrm{l} / \mathrm{s}$, following major rainfalls, suggesting a possible direct relationship between runoff and precipitation, with a residual role of catchment groundwater on the brook flow. If this is confirmed it would mean that the hydrology of the Montseny brooks is highly dependent on precipitation, and therefore its future is connected to climate change, the predictions of which have been ominous so far.

The water temperature readings have been available for three years and show the expected annual cycle values and different patterns between streams. As expected, especially in relation to the evolution of the maximum values, almost all streams reached a temperature maximum in the summer of 2019, when these values were recorded and were clearly higher on average than for the other two years. The seasonal temperature amplitude, the difference between the annual minimum and maximum, is $12^{\circ}$ in most streams. There are a few streams where the temperature in the winter is less than $5^{\mathrm{o}}$ on average, while just one of them stands out with several months being below the average, which is normal since it is at the highest altitude. If we compare these data with the daily variations in water temperature, it can be said that, at the data logger location point, none of the streams have ever been without water, as the stream's thermal amplitude does not reach values which are repeatedly high enough for them to be taken into consideration.

Many problems have arisen when monitoring flow rates with pressure sensors, mainly because of the sensor installation design was inadequate for these streams. Sediment entered the sensor tube and altered the height of the sensor every time it was extracted to obtain the data. Additionally, the large flow increases in autumn damaged many of the tubes due to the water flow's force. Thus, the installation system had to be redesigned and the sensors reinstalled in early winter. As a result, the sensor data is discontinuous and must be recalibrated with new flow measurements for each period in which the position of the sensors has changed. Even so, the data obtained provided some results. Some characteristics regarding these streams' flow regimes can be observed and, in general, there is a response to rainfall, with punctual increases in flow linked to episodes of rain and a period of discharge. The data also show that the accumulation during rainfall periods leads to a more prolonged discharge over time and the maintenance of a greater water flow.

It seems that there is a certain resilience in the flow at times when rainfall is scarce and an example of this was the end of this year's winter and spring seasons, where the flow decreased progressively over time. These decreases are not the same for all streams, and it could indicate different behavioral patterns in basin discharge in each of them [44]. At present, there are 224 flow measurements available. This data shows the basal flow rate for most of the streams is lower than $41 / \mathrm{s}$, with values below $11 / \mathrm{s}$ in one of them [44].

\subsubsection{On-site Hydrological State monitoring.}

A total of 264 visits were made to the 12 streams and these were carried out by rangers for more than 3 years, with three droughts during this period. The frequency is uneven, as more visits were attempted in the transition periods between the dry season and the period of increase in autumn flow. The frequency of these visits has been adjusted based on the first set of data.

Despite there being a link to the lack of rain, it is clear that, although they do not dry out completely, there are sections with fairly long subsurface circulation but these have been affected by other factors such as the old accumulations of land due to the creation of slopes. Despite the fact that there were times with no water in the studied sections, these sections never actually completely dried out. The data show that only two of the locations 
with newts always have circulating surface water. The other streams have had more periods where surface water was in disconnected ponds (at least one). In 2018, all locations presented water states with flow connectivity throughout the year, even during the summer, and with states of higher flow than in 2017. In 2019 they have returned to a state of low flow while surface flow disappeared in the summer months. Thus, it seems that the lack of surface water during the dry season is variable and probably linked to rainfall and that there are streams which are greatly affected by this drought and which lose surface flow for longer. Other locations have a highly constant hydrological state with continuous water flow. The data show that the hydrological regime at the different locations, which are inhabited by the newt, depend on precipitation in different ways: there are streams whose hydrological regime is greatly conditioned by precipitation, as is be the case in three of them which have smaller drainage basins. On the other hand, there are others that are more independent because the specific location has a large basin area or is close to a water fountain.

\subsubsection{The hydromorphological Montseny Brook newt habitat characterization}

The hydromorphological habitat for streams which the newt inhabits are characterized by great slopes, formed by a repeated concatenation of falls, soft riffles and slow waters which are never too deep and which have an unstable riverbed, dominated by rocks, pebbles, and gravel. Flow speed in basal discharge is low. Dense surrounding vegetation differs in its specific composition for every brook but it mainly consists of deciduous trees, which lead to a significant input of fallen leaves in the riverbed. This is the main organic input in the stream system, as the autochthonous primary production is really low (Chlorophyll a concentration under $60 \mu \mathrm{g} / \mathrm{cm} 2)$, due to low sunlight penetration. Relatively high concentrations of large organic matter (LBOM) and fine organic matter (FBOM) were recorded. Vegetation cover plays an important role in water temperature, preventing an increase where there is a greater degree of cover.

Flooding waters have extremely low conductivity, are poor in inorganic nutrients (Phosphates, Nitrates, and Ammonium) and are rich in oxygen concentration. Surface structure (presence and length of running waters) and the length of subsurface water flow have a direct correlation with oxygen concentration. There were no significant differences when comparing seasons. The flow diminished in most of the brooks, but it did not entail major changes in other variables.

No significant differences in the habitat have been found between brooks which are inhabited by the newt and those where the newt is not present. The application of a Generalized Linear Model (GLM) with logistic function for each variable does not show a significant model (chi-square test $\mathrm{p}>0.05$ ) for all cases, indicating that none of the measured variables was different in the brooks with the presence of newt when compared to those without. Therefore, hydromorphological habitat variables do not seem to be the cause behind the newt's absence in uninhabited brooks. [26,27].

\subsubsection{Water chemical composition analysis}

The results obtained in the campaign that was carried out to analyse the chemical composition of the water in Montseny were conclusive. In no case did the results obtained indicate the presence of significant concentrations of toxic elements, contaminants or evaluated heavy metals $(\mathrm{Cu})$. The Montseny's headwater streams are characterized by low mineralization. The dominant anion is alkalinity, followed by sulphate and chloride, and the dominant cation is calcium, followed by sodium and magnesium. The $\mathrm{pH}$ is above 7.00 , which together with a relatively high alkalinity, indicates that surface water acidity is not an issue. Potassium is very low, and nitrate is relatively low with a large variability (standard deviation greater than the mean). Ammonium has been undetectable in many 
cases; therefore, we can consider it negligible and it will not be taken into consideration in the statistical analyses [29].

The two groups of streams do not show significant differences except for the sulphate, which presents higher concentrations in the basins where the newt has been detected (although it is not considered relevant) [29].

\subsubsection{Geomorphological analysis}

Geomorphological data of torrents [30], indicate that they have exclusive geological and hydrological characteristics that differentiate them from Pyrenean torrents or from other mountainous areas of the Mediterranean system. These differentiating features mainly correspond to sections in headwaters with a substantial hydrological gradient and which is defined by the presence of large blocks and colluvium that form morphological gaps and fissural and cavernous porosity, leading to subway water circulation and the presence of porosity between the blocks. The presence of blocks, distribution, size and stratification determine the presence of newt. There is a preference for areas with a large accumulation of blocks, with at least 2 levels of stratification, and with large blocks without imbrication as well as a high occupation of the bed. The slate substrate becomes the base of the system, outcropping in some sections of the torrents. The orientation and distribution of the massif's fracturing is not a differentiating factor and does not determine the newt's presence or absence. The number and type of discontinuity in families throughout the massif is similar in all of the analysed sections. Areas with the bed with rocky substrate occupied by blocks that form cavities of decimetric order, together with the presence of fracture fissural cavities may determine the presence of newts.

\subsection{Monitoring of wild populations}

3.2.1. Intensive surveys

In the A2 stream, the largest number of specimens are caught in spring, mainly MayJune (Figure 8a). Stream surface groundwater activity decreases during the cold period from January to March and quickly during the summer (July and August), coinciding with the torrent's dry period, which is more or less marked depending on the year. These data are in accordance with those provided by different studies $[5,10,46]$. There is also a significant increase in activity in autumn and early winter. This varies depending on the intensity in rainfall the during autumn period and there were years were this was not so evident [38,47]. For this reason, in Mediterranean environments, which are subject to strong climatic variations, it is essential to carry out long-term monitoring programs. Phenology and climatology mean that species have the tendency of inhabiting underground aquifers between the cracked rocks in the stream and this influences the timing of surveys because during dry periods, surface activity is almost non-existent. On the other hand, high levels of water flow preclude an easy observation of newts. Our surveying experience with this species advise us that the sampling program needs to be quickly re-adapted and based on the changes in the hydrologic regime of the streams, in itself derived from the climatology and pluviometry regime because the superficial runoff depends on these two factors. However, it should be noted that while patterns of spring rain do matter, we must take into account the big increases in temperatures at the end of the spring season, produced in the absence of rainfall, which leads to the superficial drying of some stream stretches, making it impossible to detect newts. In this sense, models of climatic change $[20,48]$ for the Mediterranean area forecast more irregularity in precipitation patterns, specifically more rainfall in autumn than in spring, and concentrated over a few days in some years while in others, there were heavy droughts. 
A

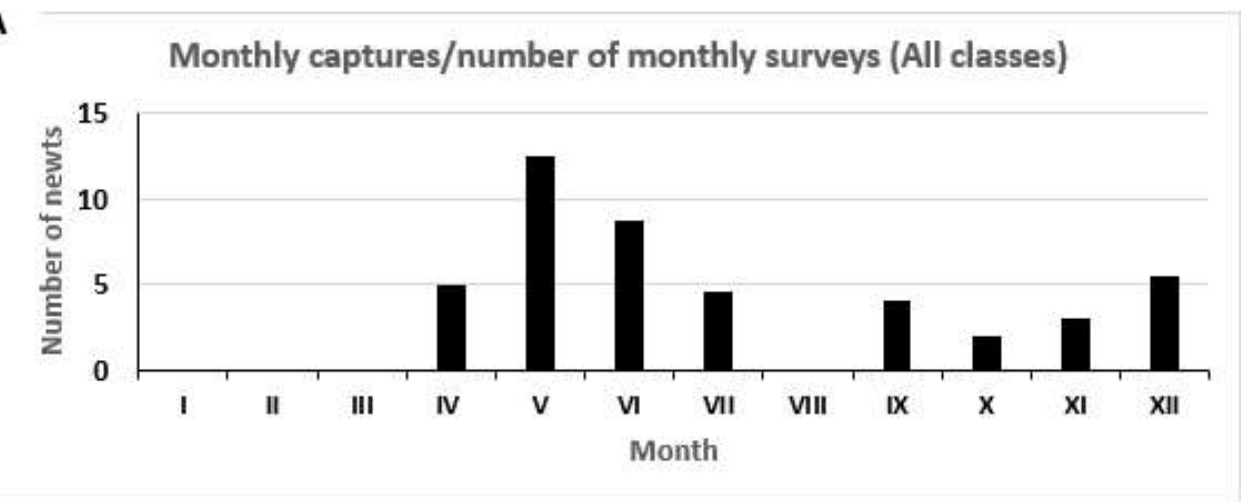

B

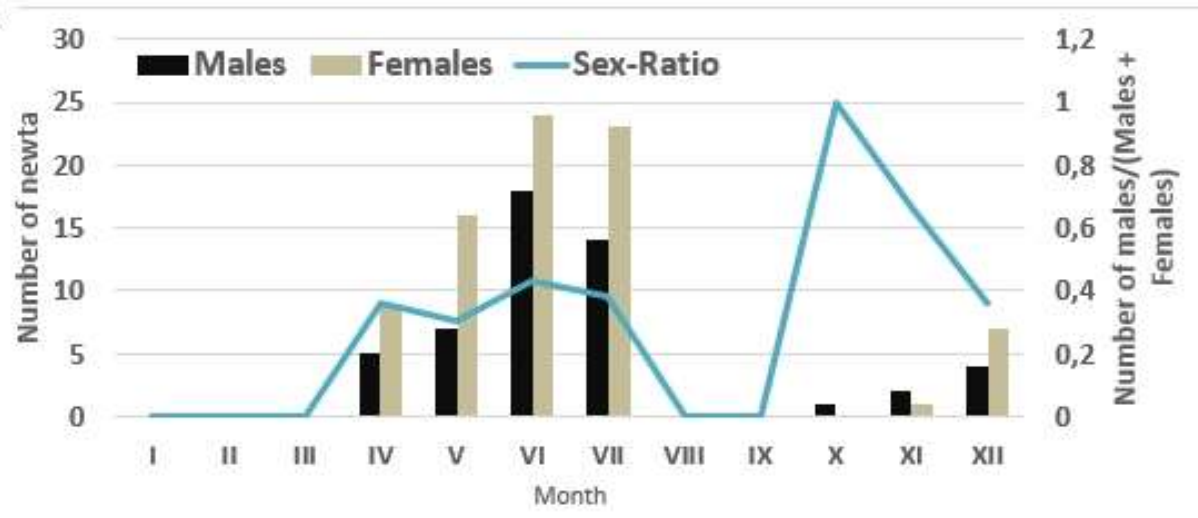

Figure 8. (A): Number of individuals from 2018 to 2020 in the A2 stream, captured by surveys in relation to number of surveys for each month. (B): Monthly Sex-Ratio in the A2 stream and number of males and females captured each month.

The average of sex-ratio obtained is favourable to females (0.43), even throughout the year (Figure $8 b$ ). These observations therefore match $[5,6]$, which found that sex-ratio is clearly favourable to females in the eastern and western nuclei.

Over time, population size is not constant because the estimations correspond to surface active newts. Their estimated survival is very high $(\phi=0.999)$ and the average density of newts was 0,95 newts $/ \mathrm{m}$. These estimates are very high because the 2020 hydrologic year was extremely rainy. This data is very important because it indicates that $C$. arnoldi underground activity must be much more significant than had previously been supposed $[20,48]$. 
Table 2. Length characteristics of the streams where wild populations of Montseny Brook newt were located. Potential: potential inhabited total length of stream (in m), Inhabited: Estimated inhabited lengths (in meters). I/P: percentage of occupied length (indicator of relative stream occupancy).

\begin{tabular}{cccc}
\hline Population code & Potential & Inhabited & $\mathbf{\% ~ I / P ~}$ \\
\hline B1a & 821 & 83 & 10.11 \\
B1b & 1117 & 587 & 52.55 \\
B2 & 895 & 475 & 53.07 \\
B3 & 932 & 107 & 11.48 \\
B4 & 2220 & 782 & 35.23 \\
B5 & 804 & 654 & 81.34 \\
A1 & 3150 & 697 & 22.13 \\
A2 & 2250 & 178 & 7.91 \\
A3 & 1180 & 34 & 2.81 \\
\hline Western Range & 6789 & 2688 & 39.59 \\
\hline Eastern Range & 6580 & 909 & 13.82 \\
\hline
\end{tabular}

\subsubsection{Extensive surveys}

Only eight wild populations of $\mathrm{C}$. arnoldi are known to inhabit the La Tordera river basin and these are genetically and geographically separated into two populational nuclei (Western and Eastern -Figure 1-). All eight populations (Table 2) have been monitored by means of extensive surveying. Ten years of surveying populations of Montseny Brook Newts have provided us with more than 1600 observations of the species in their natural habitat. There were severe droughts in 2013 and 2015 and these prevented us from gathering enough data for these years.

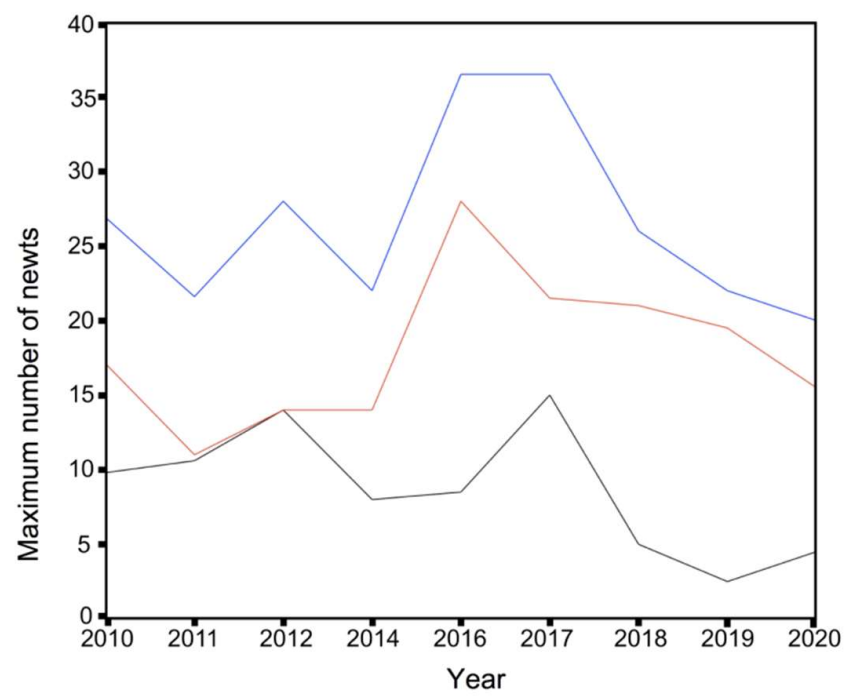

Figure 9. Maximum number of newts observed at night for every year. Lack of data during 2013 and 2015 is due to the severe drought affecting the populations that prevented us from gathering enough data (black, eastern populations, red, western populations and blue, total).

The number of observed newts per number of nights spent in stream sections for the period 2010 to 2020 and the samplings during this period showed a decline after there had 
been increases for two-years (Figure 9). This trend was more marked in eastern populations, which exhibited larger numbers of newts than in western ones. The tridimensional space generated by the three indicators provides a clear picture when assessing the vulnerability of C. arnoldi populations (Figure 10). Four populations are very isolated from the neighboring ones and in total, two of them occupy a very small proportion of the stream and yet, quite remarkably, relative abundances are high in all cases, which indicates a strong concentration of newts in small sections. The other four populations seem to be in a better situation from a conservation standpoint and show better connectivity and extensive occupation of the stream. However, and perhaps quite strikingly, only two of them additionally have a large relative abundance. Therefore, this ideal combination is found in $25 \%$ of the populations and both belong to the western area.

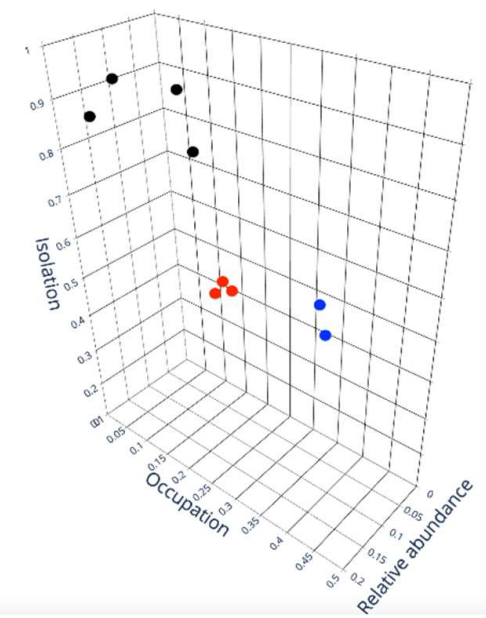

Figure 10. Tridimensional plot of the values for each Montseny Brook Newt population on three indicators: relative abundance (number of newts/m), occupation (percentage of stream occupied by the population) and isolation (dendritic index between pairs of geographically close populations). Black dots show the tridimensional position of populations with high risk of extinction given their high levels of isolation and low percentage of stream occupation. The best combination of favorable indicators, which are high connectivity, stream occupation and relative abundance, are found only in two populations marked with blue dots, whereas three populations (red dots) showed intermediate risk of extinction.

\subsubsection{New populations surveys}

The field studies $[26,27,30,43,44]$, confirm that streams where C. arnoldi is absent have similar biotic and abiotic characteristics when compared to streams where the newt is present. These results make it more difficult to select the streams in which newts could be released to create new populations. The absence of $\mathrm{C}$. arnoldi in apparently optimal streams could be a consequence of intensive human activity during the first half of the 20th century (coal production from oaks, mining activity, creation of grazing lands, forest wood extraction, slope erosivity, water catchments ...). For this reason, the anthropic activities in the first selection streams must be taken into account. Table 1 shows the new populations created prior to the LifeTM project and once it had begun. Only in populations A4, A5 and B7 out of the seven that were newly created, is there no evidence of newt presence since 2016, 2020 and 2019 respectively. However, C. arnoldi fossorial behavior and an extremely dry period in 2021 could be the reason behind these cases where there was no detection of newts.

The distribution of recaptures in the new population B8 is very similar to the distribution of released individuals in the stream. (Figure 11a). Figure 11b shows the dispersion of the 
recaptured specimens in relation to their release point. The average displacement of newts throughout 2019 was 0.76 in downstream sections. Despite this, one individual was found 20 meters downstream after the great flood, outside the marked area [49]. Although wild C. Arnoldi specimens show very little mobility and dispersal capacity in natural habitats $[5,20,48,49]$, it is expected that newts that were born in captivity and released into a new and unknown natural stream, will disperse and explore more while seeking suitable microhabitats. Results confirm this (Figure 11b). The dispersion observed is much larger than that which was estimated for wild population A2. This fact is due to the exploration of the new territory, while looking for the most suitable microhabitats. Preliminary results indicate that the population is well-established and that there have been few changes despite the floods and the summer drought.
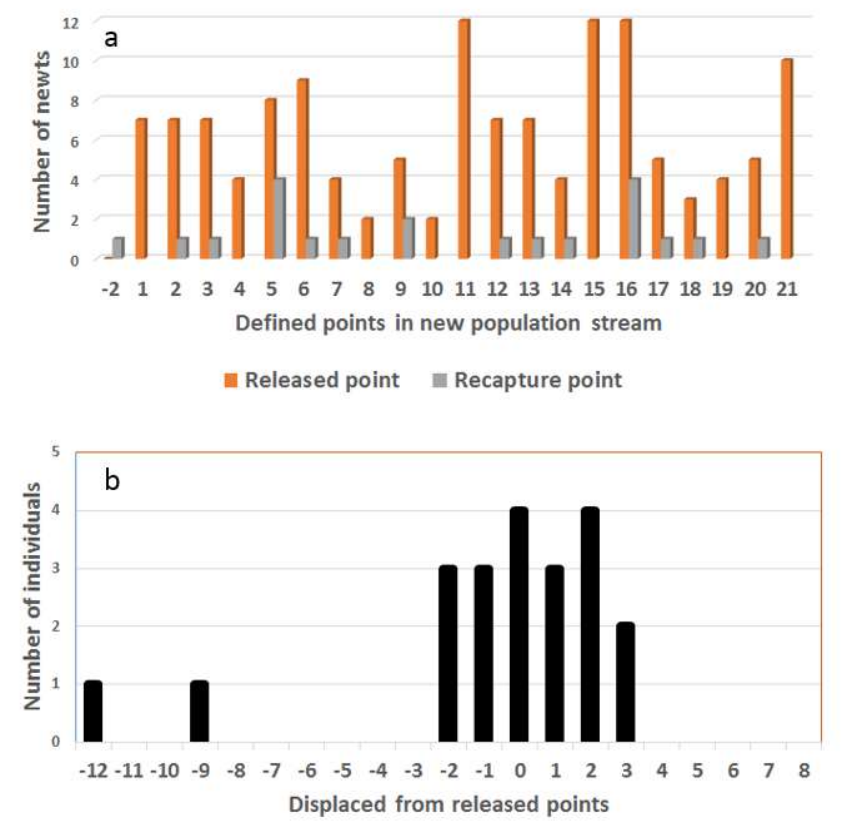

Figure 11. A: Distribution of newly released newts in the stream and the recaptures during the first year after release, Red bars indicate the release point and blue bars the recapture point. B: Displacements observed in the newly released individuals in a newly created population (A8) in the first year. Horizontal axis represents the number of displaced points from release to recapture. The positive values indicate upstream displacements and negative values indicate downstream displacements. Average of distance between points: $3.94 \mathrm{~m}$.

\subsection{Biosecurity measures}

Throughout 2018, several theoretical-practical training sessions were held for workers and users of the Diputació de Barcelona. At the same time, two biosecurity protocols were developed to be applied in the activities. An extensive one that would cover all LifeTM activities and those that would be developed in the PNRBM (i.e. fishing, ecological surveys, works, ...), while another protocol focused on educational activities to be carried out in the aquatic environment, aimed primarily at nature schools and educational centres that carry out activities in the PNRBM. The last protocol also includes a decalogue of good practices [31-33].

Finally, in 2021, information posters were placed to increase awareness of PNRBM's ban on bathing in rivers and torrents, so as to ensure the conservation of species of interest (Decree 148/92 of 9 June of the Generalitat de Catalunya). This practice is regulated by article 6.2. At the same time, for the detection of diseases, a monitoring program of emerg- 
ing diseases has been established, gathering samples from the specimens that were collected during the follow-up samplings and from other amphibian reproduction survey points within the park. This progem would allow us to detect, as soon as possible, the presence of a disease in the wild populations and to act quickly in order to prevent them from spreading. To date, only one breeding site has been identified where C. arnoldi is not found but which has tested positive for $\mathrm{Bd}$ and it is currently being controlled and managed to prevent the spread of the disease to other areas.

\subsection{Involving and engaging stakeholders}

Life TM has been the basic tool for significantly increasing resources, especially personnel, for the conservation of $\mathrm{C}$. arnoldi. The project has enabled the establishment of a multidisciplinary work team, an efficient methodology for action and the creation of collaboration protocols between administrations and individuals. This has been done to guarantee the continuity of the actions and to ensure that this endemism ceases to be a critical species in terms of its conservation status.

\subsubsection{Dissemination}

Since the start of the project LifeTM, 17 press releases have been issued and 182 news items on the Montseny newt have been published in the media. The Communication Commission has met periodically, and a total of 15 meetings have been held to reach a consensus on the communication strategy. The negative effect of visiting the riverside habitat and the dangers associated with the unintentional introduction of infectious diseases by amphibians (Bd, Bsal, Ranavirus, among others) have been highlighted. People who want to see the Montseny Brook Newt are advised to visit the BCNZoo and CRPS breeding centres. Both centres have aquariums to facilitate direct observation of the species.

With the aim of disseminating the project to residents and visitors to the PNRBM, a variety of informative material has been published. 8 informative panels (located at strategic points in the PNRBM, at the BCNZoo and CRPS breeding centres), 8 documentary capsules (on the project's YouTube channel), while there has also been a photographic exhibition and an information leaflet has been produced in three languages (16,500 copies distributed). The project's website (http://www.lifetritomontseny.eu) has received more than 55,000 visits since its inception (July 2017); it has disseminated 125 news items and issued 10 quarterly newsletters. The YouTube channel has 121 subscribers and has received more than 8,200 views; the Twitter channel has 890 followers.

\subsubsection{Education}

The exhibition "My name is Calotriton and I only live in Montseny" was inaugurated in May 2018 and has travelled to 17 of the 18 municipalities that make up the PNMRB. It has received 20,712 visitors (schoolchildren and individuals) since its inauguration. From September 2021, the exhibition will continue to travel around the Library Network of the Diputació de Barcelona. The educational program "El Montseny a l'escola" (http://www.elmontsenyalescola.cat) has allowed 2,450 pupils to participate in the didactic material and 224 children in the workshop to make a plaster newt. The new education and breeding center at BZoo has become the benchmark facility for the Montseny brook newt and has received almost 500,000 visitors since its inauguration (June 2018). A total of 13,800 people (mostly school groups) have carried out activities on the Montseny newt, guided by the zoo's educational staff (Figura 12) The BCNZoo website also has a section with several online proposals for discovering the species. 


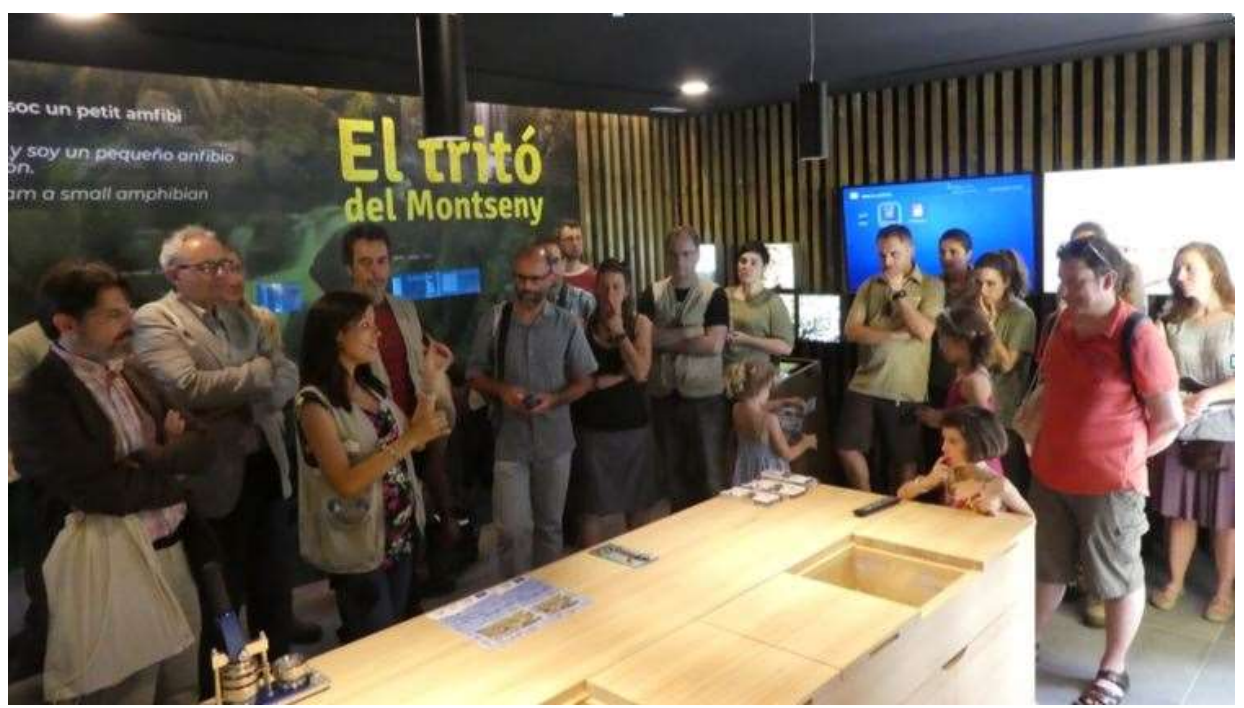

Figure 12. Educational and breeding centre in $\mathrm{BCNZoo} \mathrm{has} \mathrm{become} \mathrm{the} \mathrm{benchmark} \mathrm{facility} \mathrm{for} \mathrm{the}$ Montseny brook newt. More than 13,000 people (mostly school groups) have carried out activities around the Montseny brook newt, guided by the zoo's educational staff. This center and the one located in Pont de Suert have adapted facilities to be able to observe the Montseny brook newt and prevent people from moving to areas, which the wild populations inhabit.

The manual "Infectious diseases in amphibians. Manual of good environmental practices in educational discovery activities" (5,000 printouts), was aimed at environmental education organizations and schools; and the protocol "Biosafety: health protocols for activities that involve direct or indirect interaction with amphibian populations in the natural environment", was basically aimed at works contractors and scientific organizations that carry out activities in aquatic environments [31-33].

\subsubsection{Involvement of local landowners}

Seventy meetings have been held with forest owners since the start of LifeTM. This has led to the involvement of 9 estates which the newt inhabits in the Montseny area. A plenary meeting has also been held with 16 estate owners where the Montseny newt lives or that are potential newt introduction sites. The aim of the plenary meeting was to present the actions carried out on private and public properties. Listening to the opinions of the owners involved has allowed us to seek the future involvement of the rest of the owners. A basic tool for cooperation with local landowners has been the land stewardship contract. This is a long-term collaboration contract (twenty years) for private properties within the PNMRB. This agreement promotes strategies to aid the conservation and responsible use, in a sustainable and respectful way, of the natural, cultural and landscape resources and the values behind these (involving the forest owner). The main objective of the agreement is to ensure the conservation of the Montseny newt and its habitat. In general, the contracts' specific objectives for these private estates have been the following: 1 . To ensure that traditional activities are in line with the LifeTM. 2. To make the conservation of the Montseny Brook Newt and its riverside habitat compatible with the orderly development of forestry and agricultural activities. 3. To increase the streams' hydrological quality and their ecological balance, adequately purifying waste water, remodelling their current water catchment system and promoting the use of rainwater. 4. To improve the streams' fluvial connectivity and to restore the native riverside woodland. 5. To implement good environmental practices.

\subsection{Involvement of the scientific and technical field}


The project has been disseminated in 46 conferences, presented at local, national and European technical conferences and congresses (4,945 attendees in total). Several conferences have been held to exchange experiences between different Life projects: LifePirOs and LifeLimnoPirineus, LifeWetFlyAmphibia, LifeAunwauenAmphibian, LifeGoProFo Italy, HydrologyLife and FreshabitLife de Finlàndia. In order to involve a scientific team, a commission of hydrology experts has been set up. This commission has already met three times since 2019 and it intends to provide advice on the monitoring of established hydrological parameters, mainly thanks to the Life project, and to develop a Long-term Strategic Hydrological Monitoring Plan to benefit not only the Montseny newt but the entire Montseny massif. 3 hydrology conferences have been held with the participation of 20 scientists with expertise in hydrology who joined from 14 different institutions [50,51]. In the field of foresters and forest managers, a Manual of Good Environmental Practices has been developed [52]. Over the course of 2022 it will be presented to forest estate owners and technicians from the administrations involved in forest management with the aim of discussing it and reaching a consensus on the regulations that must be complied with within the PNRBM.

\subsection{Establishing proper legal coverage and define long-term strategic planning}

After consultation with those responsible for the Habitat Directive in Spain, they decided that C. arnoldi is a species of interest in the EU which requires strict protection, because it's a split of the Euproctus asper, which is already included in the Annex IV of DH 92/43/CEE. But as a result of the efforts made, E. asper was divided into two species, C. arnoldi (Code 6920) and C. asper (Code 6944), in order to prepare the sexennial reports (Art. 17 of DH).

A technical document on the recovery plan has been developed, and it is expected to be formally approved before the end of LifeTM. This plan outlines its biology and ecology, it makes a diagnosis on its state of conservation, it uncovers its threats, it delimits its geographic scope, it proposes information and education measures, and it establishes a periodic evaluation procedure. Monitoring, breeding, introduction and habitat management programs are also included.

In order to improve the protection of the streams where the brook newt lives, different lines of work have been established. Work is being done on two strict protection figures within the brook newt's distribution area. i) Supervised management zone has been established on private land and this involves a land stewardship contract, in order to manage habitat conservation targets. These zones have a width of between $50 \mathrm{~m}$ and $100 \mathrm{~m}$ on each side of the streams. ii) Nature reserve zone is a legal figure where exploitation of natural resources is banned. Currently, taking advantage of the drafting of the PNRBM's protection plan, in the framework of new legislation of Montseny Natural Park (D.127/2021), it's intended that most brook newt population will be included inside this zone. Another working line is to ensure that the majority of the newt population are on public land. To achieve this objective, 87 ha with streams that have brook newt populations have been purchased, and negotiations are underway for a land exchange in two private properties. A third working line is in relation to visitor control, through the review of advertisements on social networks for herpetologists, field surveillance by rangers, the elimination of signposted hiking trails near brook newt populations, and the cooperation with the police in detecting and prosecuting poachers.

\subsection{To eliminate or minimize threats in riparian habitat}

Over the last four years, we have improved water quality of the streams which $\mathrm{C}$. arnoldi inhabits by employing tertiary treatment of waste water from isolated houses and public amenities. After establishing primary (sediment storage) and secondary (forced ventilation) treatments, we built artificial marshlands (Figure 13) which consist of shallow 
ponds (approximately maximum depth of $40 \mathrm{~cm}$ ) with gravel and aquatic vegetation $(70 \%$ Phragmites australis and 30\% Iris pseudacorus). Water emerging from the artificial marshland is discharged into the forest where it is filtered below ground. After the tertiary treatment, when the water is discharged it is good condition: neuter $\mathrm{pH}$ (6.7) and optimal DQOnd (74 mgO2/l), markedly lower than the maximum values ( $<125 \mathrm{mg})$. Although this is not really problematic, values of chemical compounds are slightly high $(\mathrm{N}=23.3 \mathrm{mg} / \mathrm{l} \mathrm{y}$ $\mathrm{P}=2.6 \mathrm{mg} / \mathrm{l}$ ) and we acknowledge that they need to be improved. The approximate cost of these artificial marshlands is $12.000 €$ including materials, machinery and labour.

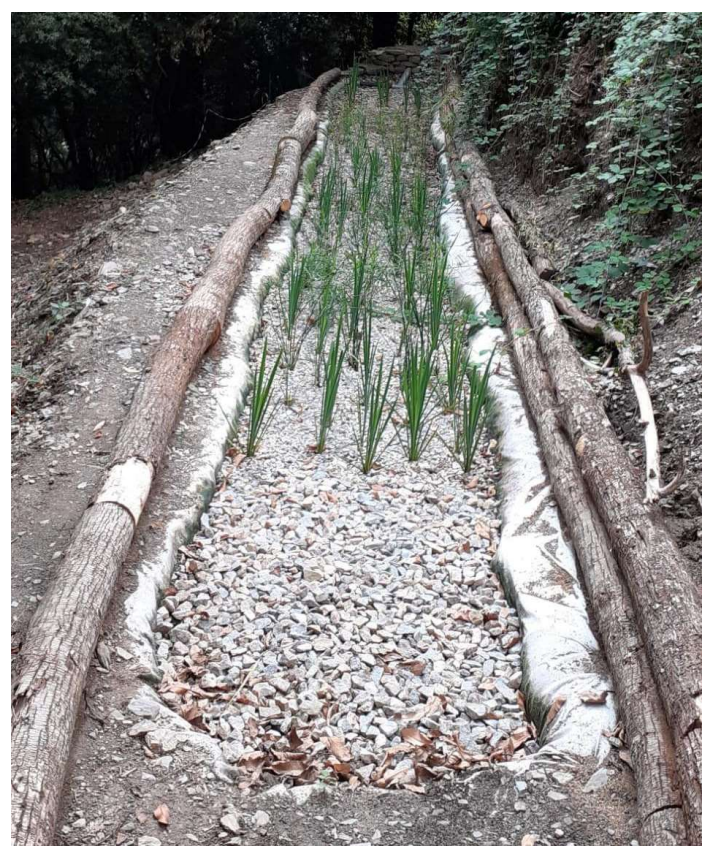

Figure 13. Artificial marshlands formed by shallow ponds with gravel and aquatic vegetation (70\% Phragmites australis and $30 \%$ Iris pseudacorus).

In order to increase the ecological flow of the streams which C. arnoldi inhabits, we are promoting the removal of shallow water catchments, the remodeling of existing water catchments, the transformation of sprinkler irrigation to trickle irrigation and the utilization of rainwater. Some landowners do not have permissions for water catchment. In these cases, we provide them information to process the legalization of water exploitation. The Catalan Water Agency (ACA), the public administration with competences to establish, after receiving a report from the PNRBM, whether water catchments must be legalized or dismantled because of their negative impact, carries out this procedure. During the last four years we have removed six water catchments directly affecting populations of C. arnoldi and this was entirely financed by the landowners to avoid future fines.

From June 2020 the owners of legalized water catchments must ensure sustainable water use and the maintenance of ecological water flow (based on legislation 2000/60/CE, DL. 3/2003, D. 380/2006 y D. 1/2017). The LifeTM project advised and promoted the modification and improvement of four legalized catchments in order to ensure ecological flow in streams inhabited by populations of the Montseny Brook Newt. In order to do so, mechanisms avoiding water extraction when water tanks are full were installed. (Figure 14). In addition, distribution boxes were installed to restrict the amount of water available for exploitation and which is legally allowed. The cost of each distribution box is approximately $3.500 €$. 


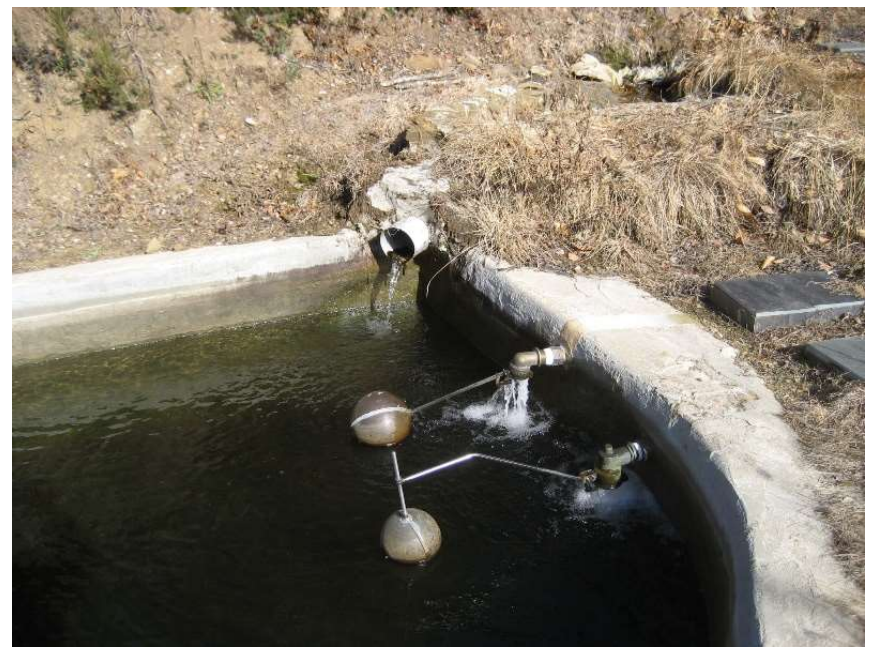

(a)

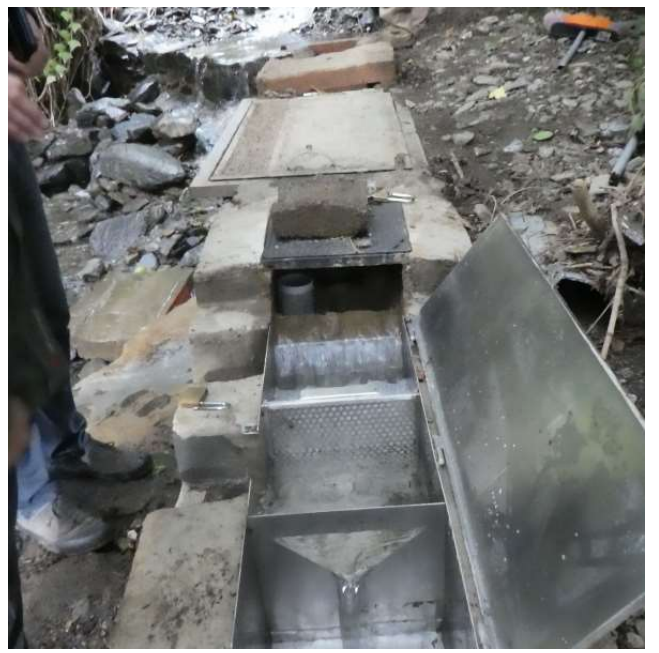

(b)

Figure 14. Installed mechanisms which regulate water extraction (a) and distribution boxes (b) restricting the amount of legally allowed water for exploitation.

In the hydrologic sub-basins where streams inhabited by C. arnoldi are located, livestock and farming are two important consumers of the water provided by water catchments. In order to diminish water over-exploitation, we are currently implementing two actions. i) Changing irrigation systems and ii) rainwater harvesting (Figure 15).

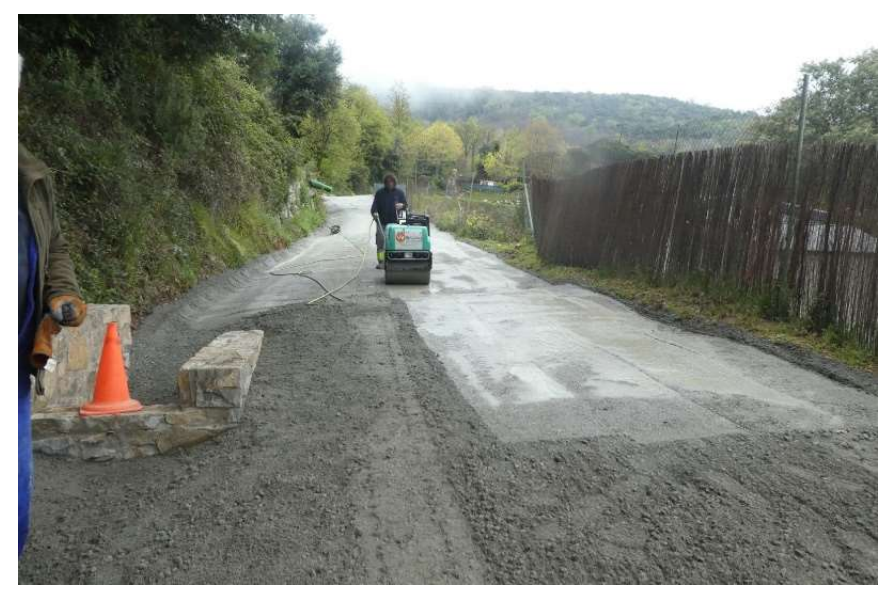

Figure 15. Rainwater harvesting by paving roads and rainwater collection ditches.

i) We changed from spray irrigation to drip irrigation because the first has a water loss due to runoff of $74 \%$ whereas the second method allows the use of $90 \%$ of the water [53]. We have removed drip irrigation in an area of $6500 \mathrm{~m}^{2}$ which produces 60.000 plants with a mean water consumption of $20.000 \mathrm{~m} 3 /$ year. Currently, this area is irrigated by employing 65.000 droppers, thus producing a theoretical reduction of water use of 11.700 $\mathrm{m} 3$ /year. Monitoring of water use must evaluate what the real value is in terms of water saving by implementing this action.

ii) The Life TM project is promoting rainwater harvesting by reconditioning roofs and roads over of $5.830 \mathrm{~m}^{2}$ in total. We estimate it may retrieve $4.110 \mathrm{~m} 3 /$ year and direct this water to tanks, which have been installed in four properties at lower altitudes Owners also use electric or solar-powered pumps to move water to other tanks placed at higher 
altitudes. Overall, we have installed 14 tanks of different sizes according to each property's needs and subject to logistic limitations, which has led to a storage of $895 \mathrm{~m}^{3}$ in total. We estimate that this action will result in economizing $4.000 \mathrm{~m}^{3} /$ year of water from the streams inhabited by Montseny Brook newts. If we take a plant nursery where rainwater is collected over an area of $1.600 \mathrm{~m}^{2}$ and is stored in four tanks (total capacity $314 \mathrm{~m}^{3}$ ), and we take into account the current values of precipitation and evapotranspiration as well as the amount of water required for irrigation (19.500 m3/any), we estimate that there will be complete hydric autonomy for 6-8 months per year. Therefore, this plant nursery could meet its water demands during 2-4 months by taking $50 \%$ of it from the stream, and $66 \%$ during the $2 / 3$ wettest months [53]. Another practical implementation was carried out in a camping area, where we modified the roadsides to collect water over an area of $2300 \mathrm{~m}^{2}$, with an efficiency of $80 \%$. As a result, we are now able to store $1530 \mathrm{~m}^{3} /$ year of rainwater in several tanks with a total capacity of $340 \mathrm{~m}^{3}$. Annual precipitation in this area is 930 $\mathrm{mm} /$ year and evapotranspiration is $913 \mathrm{~mm}$. The mean occupation of the camping is 4000 people/year, while the mean water intake is $1185 \mathrm{~m} 3 /$ year and the mean daily pumping capacity to the upper tanks is $30 \mathrm{~m}^{3} /$ day. Based on these data, we estimate that the system may meet all of the camping's water demands [54], a conclusion that will be confirmed during the monitoring process in the coming years.

The conservation of the riparian forest has focused on two main lines of work, i) the restoration of the autochthonous forest located in the secondary basins where the species lives and (Figure 16), ii) the removal of barriers crossing the streams.

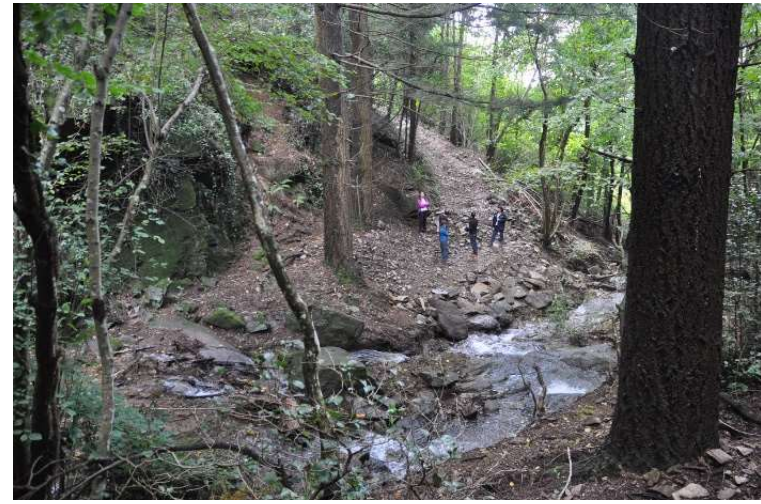

(a)

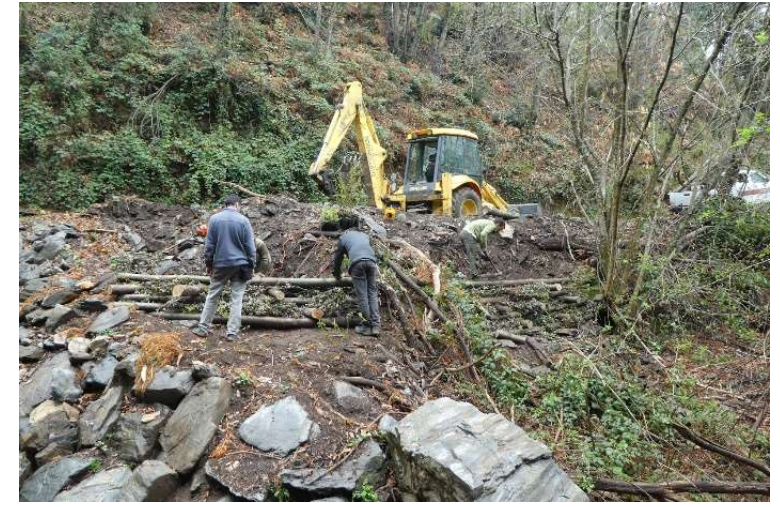

(b)

Figure 16. Restoration of the autochthonous forest placed in the secondary basins where the species lives using bioengineering techniques and traditional materials from the forest. The kind of installed structures varies according to the characteristics of the slope and the length of the affected section. (a): before restoration. (b): during restoration.

i) In order to facilitate the spread of the tree cover over the streams while simultaneously maintaining environmental humidity and decreasing water temperature, about 700 $\mathrm{m}^{2}$ of riparian forest have been recovered and the growth of autochthonous species has been encouraged (Sambucus nigra, Alnus glutinosa, Fraxinus excelsior, Corylus avellana). About three hundred of these specimens being planted in restored areas formerly without tree cover. LifeTM project also attempted to reduce the discharge of sediments by erosion and we built, using bioengineering techniques and traditional materials from the forest, transversal barriers, with the help of a team of professionals and environmental volunteers. The type of structures that were installed vary according to the characteristics of the slope and the length of the affected section. In total, more than a thousand meters of barriers were installed. Exotic conifers were planted in the Montseny massif during the second half of the past century because of their fast growth and the fact that they were highly profitable. However, these trees require huge amounts of water. For this reason the 
LifeTM project has already cut down 3,7138 ha of exotic conifers (Pseudotsuga menziesii, Pinus ponderosa, Pinus sylvestris, Cedrus sp), reaching a total $530 \mathrm{~m}^{3}$ in timber on public land and more logging is planned on private lands before the end of the LifeTM project. The open spaces created by this logging will be managed to naturally regrow an autochthonous forest with a high diversity of plant species.
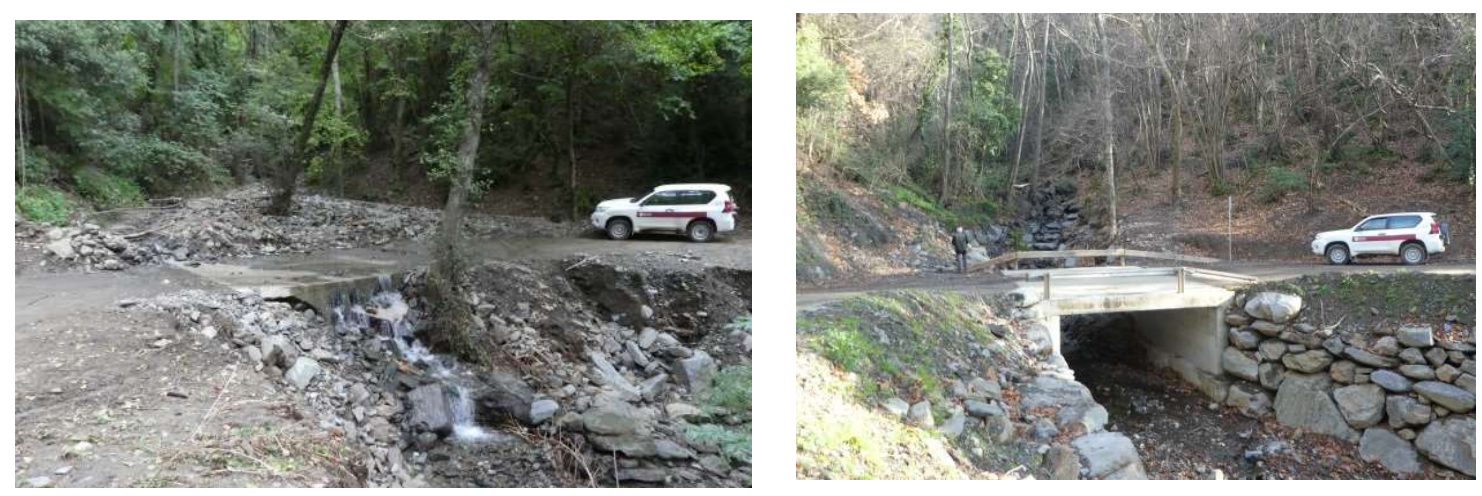

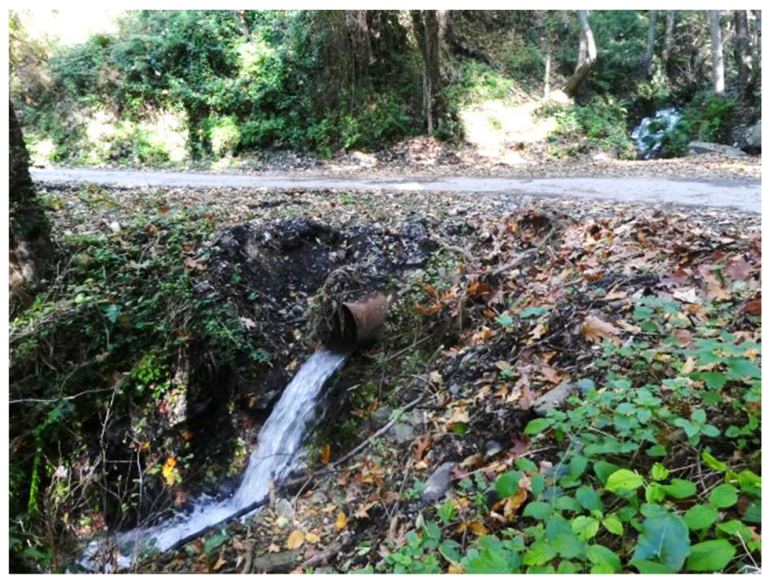

(a)

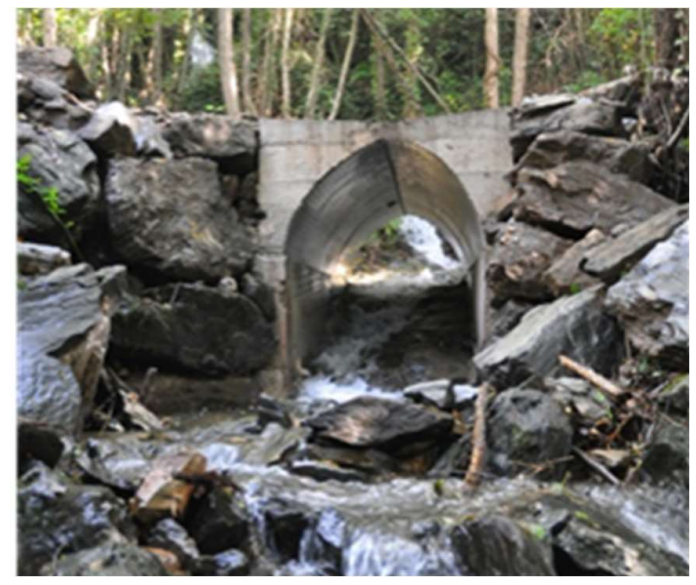

(b)

Figure 17. Modified bridges to recover the natural stream bed and to allow the displacement of aquatic fauna along them. (a) images: before recovering structure. (b) images: after recovering structure.

ii) In order to increase the number of stream sections that have optimal connectivity for all aquatic organisms, LifeTM project removed eight forest tracks and built fifteen bridges (Figure 17) of different types according to their level of use, while recovering the natural streambed to allow the movement of aquatic fauna along it. Until 2016, the streams inhabited by wild populations of $\mathrm{C}$. arnoldi consisted of 128 isolated sections, from 4 to 2170 lineal $\mathrm{m}$, with only $37 \%$ being longer than $150 \mathrm{~m}$. The launch of the Life project led to the removal of barriers in 23 stream sections so far, raising the maximum length of these sections to $6330 \mathrm{~m}$, and improving the connectivity by $3 \%$, (40\% sections with larger than 150 lineal $\mathrm{m}$ ). The most relevant work has been done in two of the eastern streams, disconnected at the beginning of the project, with sections under 50 lineal meters of connectivity and this was improved to more than $6 \mathrm{~km}$ without any barrier. At this time, after removing all the barriers, we have achieved optimal connectivity in the eight streams that host natural populations of $C$. arnoldi. 


\section{Discussion}

One of the LifeTM project's main successes has been to work with multidisciplinary teams (formed by biologists, foresters, hydrologists, geologists, environmental engineers, civil engineers, environmental educators, journalists, lawyers, ...) and the creation of committees based on expertise: hydrological and species experts working to create new populations. These two factors have made it possible to have a cross-sectional view of the various questions and doubts that have arisen throughout the project. Undoubtedly, the sharing of different points of view by different specialists has led to decision-making, which is much more relevant to the actual problem. The actions proposed in the LifeTM project have in many cases exceeded the capacity of the project itself, mainly due to problems that have arisen in the management of $C$. arnoldi habitat, which is mainly located on private land. However, land purchase or exchange and stewardship agreements as well as actions related to the efficient use of water resources, although incomplete, can be regarded as another success and as a good result of the work carried out as part of the project.

The restoration of the riparian habitat is a job that does not yield immediate results. The replacement of a non-native plant community for a native one requires a much longer period than the actual duration of the LifeTM project. However, some actions such as creating barriers against erosion and the removal of barriers that cross streams have been effective. For example, the intensive study of the A2 wild population revealed that the bridge that crossed the population exerted a barrier effect for connectivity between both sides of the torrent [38]. The remodeling of this bridge resulted in the connectivity of both populational subgroups, according to the results obtained by [47].

The effects of global climate change on C. arnoldi is, in some aspects, similar to the plight of many other amphibians. Changes in temperature or precipitation volumes have the potential to produce shifts in phenology and timing of reproduction [55-57], and there is evidence of earlier breeding under a shifting climate [58]. In temperate zones like PNRBM, many species have their southern limit of distribution and live in suboptimal climatic conditions which could get worse under the climatic change scenario. Precipitation has not shown a clear trend in recent decades in NE Iberian Peninsula [59], but air temperature is rising [60] and, particularly, the Montseny massif has experienced an increase of around $0.3^{\circ} \mathrm{C}$ per decade in the second half of the 20th century [20]. A temperature increase can lead to enhanced evapotranspiration [61], which eventually will result in reduced streamflow. Besides climate change, landscape cover type has an influence on water resources as well. Several catchment studies have shown that an expansion of forest cover leads to a decrease in the water yield $[62,63]$. A reduction in tree canopy cover shows an increase in annual water yield, higher for conifers than for deciduous hardwood forests [64]. Trees intercept large quantities of rainfall, from $18 \%$ (scrub) to $32 \%$ (forest) vegetation, which has great repercussions on vegetation cover and the availability of water resources [65].

In PNRBM the holm oak forest appears to be expanding upwards at the expense of beech forests and heathlands [20], which may contribute further to reduce streamflow by increasing evapotranspiration. Thus, both climate and vegetation cover changes may threaten C. arnoldi populations. [66] conclude that in the Montseny Massif, the frequency and length of low streamflow events will increase dramatically. In contrast, the risk of a catastrophic drift linked to high streamflow events were predicted to decrease. Thus, the potential change in vegetation toward an expansion of holm oak forests will be more important than climate change in determining threshold low flow conditions. Furthermore, future low streamflow conditions will pose a severe threat for the C. arnoldi 's survival and may help when taking management actions such as limiting the expansion of holm oak forest to ameliorate the species habitat and help in its conservation [66].

The direct relationship between runoff and precipitation with a residual role of catchment groundwater on brook flow has been hypothesized. If this is confirmed it would mean that the Montseny brooks's hydrology is highly dependent on precipitation, and therefore its evolution is linked to climate change and the predictions have been ominous 
so far $[20,60]$. Consequently, the survival of $C$. arnoldi populations is related to the streams' geomorphological structure. The presence of blocks and fractures in the stream bed result in a continuous underground runoff flow that ensures the persistence of newts during dry seasons in which surface water flow disappears $[27,30]$. The data obtained indicate that the populations of $C$. arnoldi are resilient in hypogean habitat during dry summer periods. The complete analysis of the flow regime in relation to the precipitation regime requires a longer and continuous time series of data that we hope to achieve in the following years. The measuring of all abiotic parameters such as temperature, waterflow and hydrological status is underway. We will continue to provide data for years to come, which will be useful to get to know the hydrological dynamics of the streams which $\mathrm{C}$. arnoldi inhabits [29].

Water is not a commercial product like any other but, rather, a heritage which must be protected, defended and treated as such (D.2000/60/EC). The Water Framework Directive (2000/60/CE) and its transposition into Catalan law (DL. 3/2003, D.380/2006, D.1/2017) are bound to ensure a rational and sustainable use of water and to maintain an ecological flow in watercourses. The law establishes a regime of ecological flow that must be implemented and which must be complied with by the owners of Surface water extractions. The LifeTM project is actively contributing to the implementation of these regulations within PNRBM.

Demographics, land-use and, climate and global change scenarios forecast a decline in freshwater supplies and an increase in water demand, especially in the Mediterranean basin [18]. Over the previous 50 years, a decline in river discharges has been observed in Spain and it has been shown that this decline was due to an expansion of shrubs and forests in formerly cultivated areas [67-70]. A simplistic conclusion would be that it is beneficial to remove all forests. But this statement is totally wrong because vegetation recovery is generally thought to provide important environmental benefits, such as increases in carbon sequestration [71,72], and to be the best alternative for nature conservation and biodiversity [73). Moreover, forests noticeably reduce runoff coefficients and slightly decrease annual flooding, a fact which can be explained by the effects of rainfall interception and forest water consumption that reduce soil water content and limit catchment hydrological responses [67,74]. Changing water availability and demand will require the implementation of mitigation strategies to improve the management of water resources. This requires a good understanding of the effects of land-use changes on water resources and the application of innovative land- and water-management strategies. Such strategies include forest management within the watershed scale, and water use and management based not only on efficient water consumption and water supply infrastructure but also on a more sustainable use of the land. [18,75].

The regulation of water catchments and the sustainable use of water resources through stormwater collection is one of the actions taken, because C. arnoldi habitat benefits from the increase in the ecological flow. However, even surprisingly, it is difficult to reach agreements with the owners. In the cases where this was implemented, a water autonomy of 6 to 8 months per year has been achieved, using exclusively rainwater, except for the summer months when there is a demand for water from the torrent, but with a reduction of between $50 \%$ to $44 \%$ in relation to the current catchment [53]. In the case of camping sites, the water consumption is lower and possibly the water automation will last the 12 months of the year [54]. The restoration and improvement of stream-cross trails are fundamental to recover brook flow continuity. To monitor these, data loggers have been placed in brooks where restoration has been planned. Additionally, sediment traps have proven to be efficient in assessing sediment movement and deposition due to the riverside restoration.

Despite the species' very small geographic range, its distinct populations experience environmental spatial heterogeneity $[35,76]$, which may drive the differences we found in their demographic parameters [35]. The extensive survey highlights that the estimated survival rate is lower in the eastern population than in the western population, whereas 
population size follows the opposite pattern. One potential explanation is that larger population density increases competition for resources which leads to higher mortality [77]. The estimate on demographic parameters and recapture probabilities were relatively low, which most likely led to the uncertainty with regard to the demographic parameters. Firstly, newts spend most of their time within the interstitial hypogeum environment of the stream bed. Secondly, we avoided removing rocks to locate newts to limit the impact of the study, but this is likely to have decreased capture and recapture probabilities. Finally, eastern and western streams' physical environment was different: the stream bed in the eastern population is covered by rocks and it lacks big and deep ponds, whereas the western population inhabits a succession of very small waterfalls, riffles and welldefined pools.

Intensive monitoring of an eastern population through active searches $[38,47]$ resulted in higher population density values when compared to an extensive survey [35] due to the higher number of captures and recaptures. This could suggest that active searches by lifting stones is a more suitable methodology for demographic studies. While this may be the case but the effort required to carry, it out for all populations is unaffordable for the LifeTM project and therefore to estimate global trends, it is better to use the suggested methodology for extensive monitoring. However, the demographic data obtained with intensive monitoring are essential to estimate the ecological parameters needed for modelling new populations and to estimate the probability of survival and the carrying capacity of the streams selected to create it [24,25].

Prey availability [26] in streams running over beech forests may be greater, as it was also recorded for the sister species Calotriton asper $[78,79]$. The eastern stream also has greater availability of interstitial microhabitats as refuges, and altogether these differences may result in larger population densities in the eastern population. $[37,80]$, indicate that habitat parameters affected the small-scale distribution and abundance of Calotriton asper in the streams. These results match those produced by [35], which highlight that the differences in C. arnoldi habitat would explain the differences in demographic parameters between the two analyzed populations of the Montseny Brook Newt.

The new population established shows greater dispersal than individuals in the wild population, which may be a consequence of their previous life in captivity or due to the search of optimal environments in a new habitat [49]. On the other hand, the weight loss of the recaptured individuals after a year in relation to the time of release gives an average weight gain of $1.36 \%$ with a standard deviation of $10.67 \%$ [47]. However, it is still too early to say that the models developed for the creation of new populations are actually fulfilling their function and that the newly created populations are actually establishing themselves. It is important to emphasize that the creation of the new populations commission and the adjusted demographic data obtained in the field studies with regard to the wild populations $([47,35]$ have allowed us to obtain very precise theoretical models $[24,25]$.

Monitoring of endangered species is mandatory in order to provide managers with useful information to repeatedly evaluate the state of conservation and implement actions to improve the quality of their populations. However, this kind of programs is bound to face not only logistic and budget limitations but also difficulties, mainly due to the species' biology affecting its detectability and as well as those related to affordability when sampling their habitat. Thanks to the long period of samplings, we were able to detect the persistence of the species in critical periods of severe droughts and establish an objective grading of their natural populations' vulnerability. However, the detectability of C. arnoldi greatly depends on the occurrence of environmental conditions such as temperature and hydroperiod. The optimal combination of ideal conditions rarely happens for all the sampled populations during the surveying season. It is therefore likely that the variability in the indicators we gathered is a combination of population demographic fluctuation with detectability issues. For these reasons, only the persistent absence of observation year after year during a long period of sampling can be understood as evidence of population extinction. Despite these criticisms, population monitoring of Montseny Brook Newts is a 
mandatory tool for the species conservation and even more so when we take into account the rarity of programs involving decades of monitoring in amphibians.

Biosecurity measures and protocols have clearly proven their effectiveness. Despite the unique detection of $\mathrm{Bd}$ in one of the points, which was caused by the illegal release of a non-native amphibian species of the PNRBM (far from C. arnoldi distribution area), none of three diseases surveyed (Bd, Bsal or Ranavirus) has been detected in any wild or newly created population. This indicates that our methodology is the appropriate one to prevent the entry of pathogens into the wild habitat of the species. Bd does not seem to affect C. arnoldi, unlike Bsal, which causes its death [22]. The location of Bsal in a nearby area outside the PNRBM requires us to be extremely strict when implementing biosafety protocols in the basin inhabited by C. arnoldi. On the other hand, there are no data on the effects that Ranavirus has on C. arnoldi, but its recent expansion in the north of the Iberian Peninsula forces us to prevent it even more $[81,82]$.

Genetic results indicate that there is an ancient isolation between the eastern and western subpopulations and that there is currently no gene flow between them. For this reason, the LifeTM project has treated both subpopulations as two distinct units both in terms of population management and breeding centers and the creation of new populations. However, if in the future global change endangers the species in its natural area, there would be the possibility of creating hybrid populations because what would really be endangered is the species. This is an objective not raised in the LifeTM project, but should be discussed in an experts committee, in order to reach a consensus and it would require the Generalitat de Catalunya's approval. It is the administration responsible for the species conservation, as the Recovery and Captive Breeding Plan prepared by them raises the treatment of the two subpopulations as differentiated evolutionary units.

As mentioned above, within the species potential distribution area in the upper La Tordera river basin, there are no differences between the torrents where the species lives and where it is not currently found. None of the hydrological, morphogeological, riparian habitat or trophic availability variables show differences between torrents. Therefore, the most plausible hypothesis is that land uses in the last 150 years may have caused the rarefaction and disappearance of the species in many torrents. Mining, carbonization, the transformation of forest masses into pastures and the consequent increase in the insolation of torrents and the contribution of sediments and chemical pollutants as evidenced by the high presence of $\mathrm{Cu}$ in some courses, is probably the primary cause for the species status.

Swot matrix is shown in Table 3. SWOT (strengths, weaknesses, opportunities, and threats) is a strategic planning technique used to help a person or organization with opportunities and threats related to business competition or project planning.

\subsection{Management proposals:}

- $\quad$ Research and monitoring should be promoted in order to manage the natural heritage and resources with technical and objective criteria, because Man's natural tendency to generalize local observations may be the source of many misunderstandings, and the truth can only be found by appropriate experimental designs and repetition of experiments.

- Changing water availability and demand and mitigation strategies to improve the management of water resources will need to continue being implemented. This requires the application of innovative land- and water-management strategies. Such strategies include forest management on the watershed scale, and water use and management based not only on efficient water consumption and water supply infrastructure but also on more sustainable use of the land. Moreover, regulation of water catchments and the sustainable use of water resources through stormwater collection is one of the actions, which need to be continued.

- Coniferous plantations, such as Pseudotsuga menziesii, Pinus radiate, Pinus ponderosa, Pinus nigra and Pinus uncinata, must be removed in the protected areas, in order to increase the streamflow which C. arnoldi inhabits. This is because the largest water yield increases appear to be those associated with the removal of conifer forest. 
- It is highly recommended to promote the rewilding habitats looking for an old and mature forest. Because of the effects of forest thinning, water yield may depend on the age and physiology of vegetation, as tree transpiration is sometimes much higher in young individuals than in older trees.

- Open spaces such as pastures and grassland should be recovered, because a decline has been observed in river discharges in Spain over the last 50 years and it has been demonstrated that this decline was due to an expansion of shrubs and forests in formerly cultivated areas. 
Table 3. SWOT (strengths, weaknesses, opportunities and threats) at the fourth year of LifeTM project.

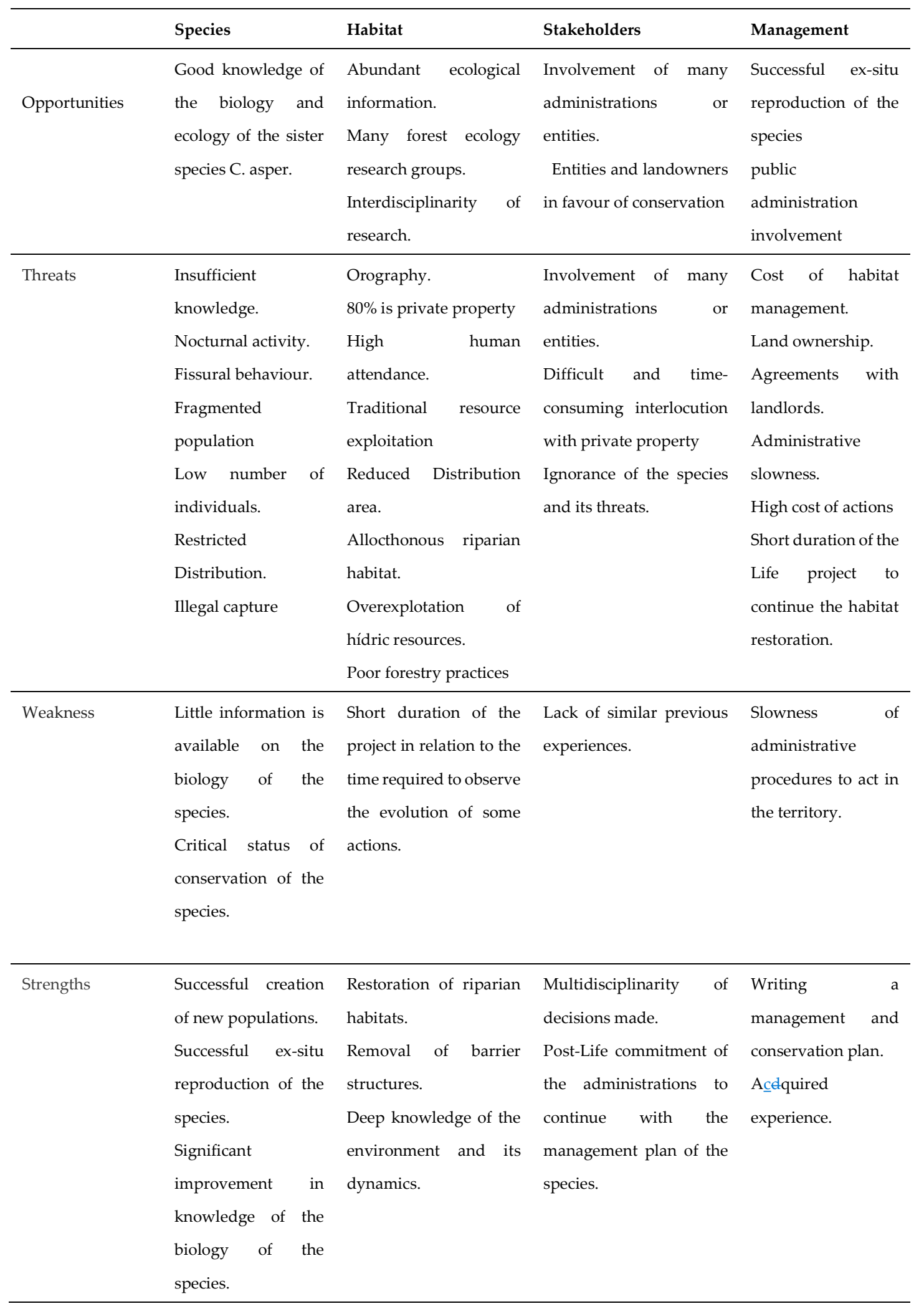

Acknowledgments: A project of this magnitude includes the participation of many people without whom it could not have been carried out. In this section, we wish to express our gratitude, for their 
important role in the project, to the professional groups of PNRBM's rangers, maintenance brigade, technical and administrative; Staff of Natural Parks of Diputació de Barcelona and Diputació de Girona, of Zoo de Barcelona, of Wildlife Service and Agents Rurals of Generalitat de Catalunya and of Forestal Catalana, private owners of PNRBM, GRENP, Agència Catalana de l'Aigua, Chester Zoo, CREAF. We also want to thank all the specialists who participated in the numerous workshops on hydrology, introductions or new populations and biosecurity. The scientific capture permits were granted by the Wildlife Service of the Generalitat de Catalunya and the Area of Natural Parks of the Diputació de Barcelona. We would like to give special thanks to the people who have been involved the most, namely JM ${ }^{a}$.Alonso, A.Álvarez, JC.Àngel, J.Anglada, M ${ }^{a} J$.Aramburu, M.Areste, J.Argemi, A.Ávila, J.Barber, C.Bares, M.Barrachina, C.Carbó, F.Carbonell, S.Carranza, R.Casanovas, X.Comas, C.Comajuana, J.Comellas, M.Comellas, R.Fradera, P.Fruitós, F.Gallart, G.Garcia, M. Giol, J.Gomà, C.Guillot, J.Latron, L.López, E.Martí, J.Melero, A.Oltra, G.Pascual, A.Pérez, I.Planas, M.Pomarol, D.Riera, J.Santaella, Ó.Soler, A.Tarragó, E.Valbuena, P.Varona, N.Vicens, D.Villero.

Author Contributions: Conceptualization, D.G. and A.M.; Methodology: all authors Validation, all authors. Investigation: all authors; Resources all authors. Writing-original draft preparation: all authors. Writing-review and editing: D.G., F.A. J.G., S.S. and A.M. Supervision, D.G., F.A. and A.M. Project administration D.G., J.G. and S.S. Funding: This research was funded by Diputació de Barcelona, Life projects of the European Commission (LIFE15 NAT/ES/000757), the Amphibian Ark and the Bin Zayed Species Foundation.

Funding: This research was funded by Diputació de Barcelona, Life projects of the European Commission (LIFE15 NAT/ES/000757), the Amphibian Ark and the Bin Zayed Species Foundation..

Conflicts of Interest: The authors declare no conflict of interest. The funders had no role in the design of the paper, in the writing of the manuscript or in the decision to publish the results.

\section{References}

1. Foley, J.A.; DeFries, R.; Asner, G.P.; Barford, C.; Bonan, G.; Carpenter, S.R.; Chapin, F.S.; Coe, M.T.; Daily, G.C.; Gibbs, H.K.; Helkowski, J.H.; Holloway, T.; Howard, E.A.; Kucharik, C.J.; Monfreda, C.; Patz, J.A.; I.C.Prentice, I.C.; Ramankutty, N.; Snyder, P.K. Global consequences of land use, Science. 2005. 309:570-574, https://doi.org/10.1126/science.1111772.

2. Gallart, F.; Llorens, P. Observations on land cover changes and water resources in the headwaters of the Ebro catchment, Iberian Peninsula. Physics and Chemistry of the Earth, 2004. 29(11-12), 769-773. https://doi.org/10.1016/j.pce.2004.05.004.

3. Bosch, J. M.; Hewlett, J. D. A review of catchment experiments to determine the effect of vegetation changes on water yield and evapotranspiration. Journal of Hydrology. 1982. 55(1-4), 3-23. https://doi.org/10.1016/0022-1694(82)90117-2

4. 4. Andreassian, V. Waters and forests: from historical controversy to scientific debate. Journal of Hydrology. 2004. 291:127.

5. Carranza, S. \& Amat, F. Taxonomy, biogeography and evolution of Euproctus (Amphibia: Salamandridae), with the resurrection of the genus Calotriton and the description of a new endemic species from the Iberian Peninsula. Zoological Journal of the Linnean Society. 2005. 145:555-582.

6. Amat, F. Estat de conservació del tritó pirinenc (Euproctus asper) a la Reserva de la Biosfera i Parc Natural del Montseny. 2005. VI Trobada d'Estudiosos del Montseny Diputació de Barcelona. 2005 119-121.

7. Carranza, S. \& Martínez-Solano, I. Calotriton arnoldi. The IUCN Red List of Threatened Species 2009: e.T136131A4246722. Access on 3 october 2021

8. Montori, A. \& Pasqual, X., Nota sobre la distribución de Euproctus asper (Dugés) en Catalunya: I primera localidad para el 27 macizo del Montseny. Publicaciones del Departamento de Zoología 1981. 6:85-88.

9. Montori, A.; Herrero, P. Caudata. Pp. 43-275. En: Amphibia. Lissamphibia. García-París, M., Montori, A., Herrero, P. Fauna Ibérica, 24, Ramos, M.A. et al. (Eds.). 2004. Museo Nacional de Ciencias Naturales, CSIC., Madrid.

10. Montori, A.; Campeny, R. Situación actual de las poblaciones de tritón pirenaico (Euproctus asper) en el macizo del Montseny. Boletín de la Asociación Herpetológica Española, 1991. 2:10-12.

11. Amat, F.; Guinart, D. Anàlisi de la disponibilitat d'hàbitat potencial per a la implantació de noves poblacions de tritó del Montseny (Calotriton arnoldi) al PN-RB del Montseny. Unpublished report. 2019, Diputació de Barcelona-Life Tritó del Montseny. 37pp.

12. Valbuena-Ureña, E.; Amat, F.; Carranza, S. Integrative phylogeography of Calotriton newts (Amphibia, Salamandridae), with special remarks on the conservation of the endangered Montseny brook newt (Calotriton arnoldi). PLoS One 2013. 8: e62542.

13. Valbuena-Ureña, E.; Soler-Membrives, A.; Steinfartz, S.; Orozco-TerWengel, P.; Carranza, S. No signs of inbreeding despite long-term isolation and habitat fragmentation in the critically endangered Montseny brook newt (Calotriton arnoldi). Heredity. 2017. 118:424435 DOI 10.1038/hdy.2016.123. 
14. 14. Amat, F.; Oromí, N.; Sanuy, D.; Carranza, S. Sexual dimorphism and age structure of the Montseny newt (Calotriton arnoldi). Amphibia-Reptilia. 2015. 36: 245-252.

15. Guinart, D; Solórzano, S.; Vicens, N.; et al. Pla de conservació del Parc Natural del Montseny. Reserva de la Biosfera. Diputació de Barcelona. 2014. 561pp.

16. Valbuena-Ureña E, Soler-Membrives A, Steinfartz S, Alonso M, Carbonell F, Larios-Martín R, Obon E, Carranza S. Getting off to a good start? Genetic evaluation of the ex situ conservation project of the Critically Endangered Montseny brook newt (Calotriton arnoldi) PeerJ 2017. 5:e3447 https://doi.org/10.7717/peerj.3447

17. Carbonell-Buira, F., Obon, E., Alonso, M., i Valbuena, E. Pla de cria del tritó del Montseny. In: Such-Sanz, A. (ed.). Activitats realitzades pel centre de fauna de Torreferrussa. Unpublished report. Departament Medi Ambient i Habitatge Forestal Catalana, SA. Generalitat de Catalunya. 2011. Barcelona.

18. Peñuelas, J.; Germain, J.; Álvarez, E.; Aparicio, E.; Arús, P.; Basnou, C.; Blanché, C.; Bonada, N.; Canals, P.; Capodiferro, M.; et al. Impacts of Use and Abuse of Nature in Catalonia with Proposals for Sustainable Management. Land 2021, 10, 144. https://doi.org/10.3390/land10020144.

19. Villero, D.; Anton, M.; Garcia, E.; Munné, A.; Solà, C.; Bonada, N.; Fortuño, P; Rotchés, R.; Guinart, D.; Solórzano, S.; Ventura, M.; Maceda, A.; Ordeix, M; Casals, F.; Ordóñez, J.L.; Sainz de la Maza, P.; Pont, S. Aigües continentals. In: Brotons, et al. 2020 Estat de la Natura a Catalunya 2020. Departament de Territori i Sostenibilitat. Generalitat de Catalunya. 2020. Barcelona.

20. Peñuelas, J.; Boada, M. A global change-induced biome shift in the Montseny mountains (NE Spain). Global Change Biology. 2003 9(2):131-140. https://doi.org/10.1046/j.1365-2486.2003.00566.x

21. 21. Martel, A.; Spitzen-van der Sluijs, A.; Blooi, M.; Bert, W.; Ducatelle, R.; Fisher, M. C.; Woeltjes, A.; Bosman, W.; Chiers, K.; Bossuyt, F. \& Pasmans, F. «Batrachochytrium salamandrivorans sp. nov. causes lethal chytridiomycosis in amphibians». Proceedings of the National Academy of Sciences. 2013.110 (38): 15325-15329.

22. 22. Martel A, Vila-Escale M, Fernández-Giberteau D, et al. Integral chain management of wildlife diseases. Conservation Letters. 2020;13:e12707. https://doi.org/10.1111/conl.12707

23. Carbonell-Buira, F.; Alonso, M.; Obon, E.; Obon, E.; Valbuena-Ureña, E. Montseny Brook Newt ex situ conservation program. AArk Newsletter. 2014. 27:11-22.

24. Villero, D.; Hermoso, V.; Solorzano, S.; Amat, F.; Guinart, D.; Brotons, L. Caracterització de l'hàbitat del tritó del Montseny. Diputació de Barcelona-CTFC. 2018. Unpublished report. 19pp.

25. 25. Villero, D.; Amat, F.; Canesa, S.; Guinart, D.; Hermoso, V.; Salgado-Rojas, J.; Solórzano, S.; Brototons, L. Avaluació de l'estratègia per ampliar l'àrea De distribució del tritó del Montseny. Planificació de la creació de noves poblacions. Unpublished report. CREAF-Diputació de Barcelona. 2019. 19pp.

26. 26. Gomà, J.; Sabater, F. Estudi dels Macroinvertebrats i Meiofauna dels torrents potencialment habitables pel Tritó del Montseny (Calotriton arnoldi). Universitat de Barcelona-FEMH-Diputació de Barcelona. 2018. Unpublished report. 17pp.

27. Martí, E.; Ribot, M. Caracterització hidromorfològica de les rieres de la conca alta de la Tordera per entendre l'hàbitat potencial del tritó del Montseny (Calotriton arnoldi). Unpublished report. 2018. CEAB-CSIC-Diputació de Barcelona. 22pp.

28. Avila, A. Time trends in the precipitation chemistry at a mountain site in noth-eastern Spain for the period 1983-1994. Atmospheric Environment, 1996. 30: 1363-1373.

29. 29. Ávila, A. Estudi de la dinàmica hidro-química de la conca del Torrent de la Mina com a zona potencial de reintroducció del tritó i Caracterització de la composició química de torrents del Montseny amb presència i absència del tritó. Unpublished report. 2018. Centre de Recerca Ecològica i Aplicacions Forestals (CREAF)-DIBA. 37pp.

30. 30. Mata, R.; Puiguriguer, M. Caracterització geològica de l'hàbitat del tritó del Parc Natural del Montseny. Unpublished report. Axial . Geologia i Medi Ambient S.L.-Diputació de Barcelona. 2019. 158pp.

31. Fernández-Guiberteau, D.; Montori, A. Les malalties infeccioses en amfibis Manual de bones pràctiques en les activitats educatives de descoberta. Gemma Pascual, Narcís Vicens i Daniel Guinart (Coord). LifeTM docs. 2020. 20pp.

32. Fernández-Guiberteau, D.; Montori, A.; Pérez-Sorribes, L.; Carranza, S. Protocols sanitaris per a les activitats que impliquin la interacció directa o indirecta amb les poblacions d'amfibis al medi natural. LifeTm docs. 15pp.

33. Fernández-Guiberteau, D.; Vila-Escarré, M.; Carraanza, S.; Ferran, A.; Pannon, P.; Picart, M.;Pérez-Sorribes, L.; Molina, C.; Montori, A.; Guinart, D. La bioseguretat, una eina imprescindible per a la conservació dels amfibis. IV Trobada d'Estudiosos de la Serralada Litoral Central i VIII del Montnegre i el Corredor. Sèrie Territori i Parcs Naturals 2020. 7:240-246.

34. Montori, A. Estudio sobre la biología y ecología del tritón pirenaico Euproctus asper (Dugès, 1852) en La Cerdanya. Doctoral thesis, Universitat de Barcelona. 2008.

35. Amat, F.; Fernández-Guiberteau, D.; Montori, A.; Oro, D. Spatial heterogeneity in the demography of the critically endangered Montseny brook newt (Calotriton arnoldi). Salamandra, 2021. 57(3):309-316.

36. Wilson, K.; Hardy, I. C. W. Statistical analysis of sex ratios: an introduction. - pp. 48-92 in: Hardy, I. C. W. (ed.): Sex ratios - concepts and research methods. - Cambridge University Press, Cambridge. 2002.

37. 37. Montori, A.; Llorente, G.A.; Richter-Boix, A. Habitat features affecting the small-scale distribution and longitudinal migration patterns of Calotriton asper in a pre-Pyrenean population. - Amphibia-Reptilia. 2008. 29: 371-381.

38. 38. Fernández-Guiberteau, D.; Montori, A.; Amat, F. Estudi demogràfic i seguiment de la població de Calotriton arnoldi al torrent A2. 2018. Unpublished report-GRENP. 2019. 29pp. 
39. 39. Carbonell-Buira, F.; Aresté, M.; Fradera, R. Final report Captive breeding program. Life Tritó Montseny. Centre de Fauna de Torreferrussa (Forestal Catalana) - Zoològic de Barcelona - Centre de Fauna de Pont de Suert. 2021 Unpublished repport.

40. 40. Phillips, S.; Anderson, R.; Schapire, R. Maximum entropy modeling of species geographic distributions. Ecol. Modell. 2006. 190:231-259. doi:10.1016/j.ecolmodel.2005.03.026

41. 41. Villero, D., Hermoso, V., Solorzano, S., Amat, F., Guinart, D., \& Brotons, L. 2018. Caracterització de l'hàbitat del tritó del Montseny. Unpublished report. 2018. Diputació de Barcelona \& CTFC.

42. 42. Phillips, S.J.; Dudík, M.; Elith, J.; Graham, C.H.; Lehmann, A.; Leathwick, J.; Ferrier, S. Sample selection bias and presence-only distribution models: implications for background and pseudo-absence data. Ecol. Appl. 2009. $19: 181-97$.

43. 43. Amat, F.; Guinart, D. Anàlisi de la disponibilitat d'hàbitat potencial per a la implantació de noves poblacions de tritó del Montseny (Calotriton arnoldi) al PN-RB del Montseny. Validació de l'hàbitat potencial pel tritó del Montseny. LIFE15 NAT/ES/000757. Unpublished report.2019. 41pp.

44. 44. Gomà, P.; Avila, A.; Comas, X.; Guinart, D.; Grau, J.; Solorzano,S. Qualitative and quantitative hydrological monitoring. Annual Report (LIFE15 NAT / ES / 000757). 2020.

45. 45. Villero, D.; Amat, F.; Canesa, S.; Guinart, D.; Hermoso, V; Salgado-Rojas, J.; Solórzano, S.; Brotons, L. Avaluació de l'estratègia per ampliar l'àrea de distribució del tritó del Montseny. Planificació de la creació de noves poblacions. Unpublished report. 2020. Diputació de Barcelona \& CTFC.

46. 46. Amat, F.; Carranza, S. Estudi demogràfic del tritó del Montseny (Calotriton arnoldi) al Parc Natural i Reserva de la Biosfera del Montseny Unpublished report. 2005. Diputació de Barcelona.

47. 47. Fernández-Guiberteau, D.; Montori, A.; Amat, F.; Carbonell, F.; López-López, L.M.; Comas, X. Seguiment demogràfic de Calotriton arnoldi de la població natural A2 i de les de nova creació B8, A5 i A6. 2019. Unpublished report. 2020. 68pp.

48. 48. Minuartia. Estudi dels efectes del canvi climàtic en el Montseny: diagnosi, impactes i vulnerabilitats. LIFE Clinomics. Acció A1. 2016. Unpublished Report. 146pp.

49. 49. Carbonell-Buira, F.; Fernández-Guiberteau, D.: Montori, A. Establishment of a new western population of Montseny Brook Newt in 2019. AArk Newsletter. 2020. 49:25-26.

50. 50. Broekman, A.; Sánchez, A. Resum executiu del cicle de trobades del Comitè Assessor d' Hidròlegs pel PNRB Montseny. Unpublished report.2019. PNRBM-CREAF.

51. 51. Cristobal-Roselló, J. Document marc per a la integració de la recerca hidrològica en la gestió del Parc Natural del Montseny - Reserva de la Biosfera (PNM-RB). Unpublished report. 2020. PNRBM- LifeTM.

52. 52. Vayreda, J.; Comas, L.; Solorzano, S.; Guinart, D. Buenas prácticas Forestales en los bosques de ribera del Montseny. Unpublished report. 2020. PNRBM- LifeTM.

53. 53. Miralpeix, $m$. Estudi a la finca de can rubi, de la transformació del sistema de reg del cultiu de plantes en contenidor existent i de l'aprofitament de les aigües pluvials i escorrentia dels camps. Unpublished report. PNRBM- LifeTM. 2018. Servei assistència tècnica reg, s.l. Núm. de valoració: 17-v/09242. Núm. d' informe: i-18/04072. Dputació de Barcelona 37pp.

54. 54. Sorolla, A.; Mota, E.; Rueda, I.; Sorolla, G.; Unzeta, C.; Ribera, S. Avantprojecte per la millora ecològica de la gestió l'aigua al xalet i el càmping de Fontmartina. Naturalea - Informe LIFE Trito Montseny. Unpublished report. 2018.

55. 55. Beebee, T. J. C. Amphibian breeding and climate. Nature. 1995. 374(6519), 219-220. doi: 10.1038/374219a0.

56. 56. Parmesan, C. Ecological and evolutionary responses to recent climate change. Annu Rev. Ecol. Evol. Syst. 2006 37:637669.

57. 57. Blaustein, A.R.; Walls, S.C.; Bancroft, B.A.; Lawler, J.J.; Searle, C.L.; Gervasi, S.S. Direct and Indirect Effects of Climate Change on Amphibian populations. Diversity. 2010, 2, 281-313; doi:10.3390/d2020281

58. 58. Chadwick, E.A.; Slater, F.M.; Ormerod, S.J. Inter- and intraspecific differences in climatically mediated phenological change in coexisting Triturus species. Glob. Change Biol. 2006, 12, 1069-1078.

59. 59. González-Hidalgo, J. C.; López-Bustins, J. A.; Štepánek, P.; Martín-Vide, J.; de Luisa, M. Monthly precipitation trends on the Mediterranean fringe of the Iberian Peninsula during the secondhalf of the twentieth century (1951-2000). International Journal of Climatology, 2009. 29(10), 1415-1429. https://doi.org/10.1002/joc.1780

60. 60. Vicente-Serrano, S.; M.; Lopez-Moreno, J.I.; Beguería, S.; Lorenzo-Lacruz, J.; Sanchez-Lorenzo, A.; García-Ruiz, J. M.; Espejo, F. Evidence of increasing drought severity caused by temperature rise in southern Europe. Environmental Research Letters, 2014. 9(4), 9. https://doi.org/10.1088/1748-9326/9/4/044001

61. 61. Wang, K. C.; Dickinson, R. E.; Liang, S. L. Global atmospheric evaporative demand over and from 1973 to 2008 . Journal of Climate, 2012. 25(23), 8353-8361. https ://doi.org/10.1175/jcli-d-11-00492.1

62. 62. Bosch, J.M., Hewlett, J.D., 1982. A review of catchment experiments to determine the effect of vegetation changes on water yield and evapotranspiration. Journal of Hydrology, 55(1/4): 3-23.

63. 63. Gallart, F.; Llorens, P. Observations on land cover changes and waterresources in the headwaters of the Ebro catchment, Iberian Peninsula. Physics and Chemistry of the Earth, 2004. parts A/B/C (11-12): 769-773

64. 64. Sahin, V.; Hall, M.J. The effects of afforestation and deforestation on water yields. Journal of hydrology. 1996. 178: 293-309.

65. 65. Llorens, P.; Domingo, F. Rainfall partitioning by vegetation under Mediterranean conditions. A review of studies in Europe, J. Hydrol. 2007 335:37-54, https://doi.org/10.1016/j.jhydrol.2006.10.032 
66. 66. Ledesma, J. L. J.; Montori, A.; Altava-Ortiz, V.; Barrera-Escoda, A.; Cunillera, J.; Àvila, A. Future hydrological constraints of the Montseny brook newt (Calotriton arnoldi) under changing climate and vegetation cover. Ecology and Evolution, 2019. 9(17), 9736-9747. https://doi.org/10.1002/ece3.5506

67. 67. Gallart, F.; Llorens, P.; Latron, J.; Regüés, D. Hydrological processes andtheir seasonal controls in a small Mediterranean mountain catchment in the Pyrenees. Hydrology and Earth System Sciences, 2002. 6(3): 527-537.

68. 68. Beguería, S.; López-Moreno, J.I.; Lorente, A.; Seeger, M.; García-Ruiz, J.M., Assessing the effect of climate change and land-use changes on streamflow in the central Spanish Pyrenees. Ambio, 2003.32 (4):283-286.

69. 69. López-Moreno, J.I.; Beguería, S.; García-Ruiz, J.M. Trends in high flows in the Central Spanish Pyrenees: Response to climatic factors or to land use change? Hydrological Sciences Journal 2006. 51:1039-1050.

70. 70. López-Moreno, J.I.; Vicente-Serrano, S.M.; Moran-Tejeda, E.; Zabalza, J.; Lorenzo-Lacruz, J.; García-Ruiz, J.M. Impact of climate evolution and land use changes on water yield in the Ebro basin. Hydrology and Earth System Science, 2011. 15:311-322. http://dx.doi.org/10.5194/hess-15-311-2011.

71. 71. Nabuurs, G.J.; Schelhaas, M.J.; Mohren, G.M.J.; Field, C.B. Temporal evolution of the European Forest sector carbon sink 1950-1999. Global Change Biology, 2003. 9, pp.152-160.

72. 72. Nadal-Romero, E.; Cammeraat, E.; Pérez-Cardiel, E.; Lasanta, T. Effects of secondary succession and afforestation practices on soil properties after land abandonment in humid Mediterranean mountain areas. Agric. Ecosyst. Environ. 2016. 228:91-100 DOI: 10.1016/j.agee.2016.05.003.

73. 73. Navarro, L; Pereira, HM. Rewilding abandoned landscapes in Europe. Ecosystems. 2012. 15:900-12.

74. 74. Llorens, P.; Gallart, F.; Cayuela, C.; Roig-Planasdemunt, M.; Casellas, E.; Molina, A.J.; Moreno-de-las-Heras, M.; Bertran, G.; Sánchez-Costa, E.; Latron, J.. What have we learnt about Mediterranean catchment hydrology? 30 years observing hydrological processes in the vallcebre research. catchments Geographical Research Letters. 2018. 4(2):475-502.

75. 75. Lana-Renault, N.; Morán-Tejeda, E.; Moreno de las Heras, M.; Lorenzo-Lacruz, J.; López-Moreno, N. Land-use change and impacts. In: Water Resources in the Mediterranean Region. ISBN: 9780128180860.Elsevier. 2020. 257-296.

76. 76. Amat F, Carranza S, Valbuena-Ureña E, Carbonell F. Saving the Montseny brook newt (Calotriton arnoldik9 from extinction: an assessment of eight years of research and conservation. Froglog, 2014. 22: 55-57.

77. 77. Harper, E.B \& Semlitsch, R.D. Density dependence in the terrestrial life history stage of two anurans. Oecologia, 2007. 153, 879-889. https://doi.org/10.1007/s00442-007-0796-x

78. 78. Montori, A. Alimentación de los adultos de Euproctus asper (Dugès, 1852) en la montaña media del Prepirineo catalán (España). Rev. Esp. Herpetol., 1991. 5:23.- 36.

79. 79. Sánchez-Hernández, J., Montori, A. \& Llorente, G.A. Ontogenetic dietary shifts and food resource partitioning in a stream-dwelling urodela community: Mechanisms to allow coexistence across seasons. Russian Journal of Herpetology, 2019. 26(3), 135-149. DOI: 10.30906/1026-2296-2019-26-3-135-149.

80. 80. Camarasa, S.; Oromí, N.; Sanuy, D.; Amat, F. Demographic Traits Variation in a Pyrenean Newt (Calotriton asper) among Lacustrine and Stream Populations. Diversity, 2020, 12, 471; doi:10.3390/d12120471

81. 81. Bosch, J.; Mora-Cabello, A.; Marquínez, S.; Price, S.J.; Thumsova, B.; Bielby, J. Long-term monitoring of amphibian populations of a National Park in Northern Spain reveals negative persisting effects of Ranavirus, but not Batrachochytrium dendrobatidis. 2021. Front. Vet. Sci. 8:645491. doi: 10.3389/fvets.2021.645491

82. 82. Montori, A.; López-Caro, J.; Jordà, A.; Fernández-Guiberteau, D. Les pandèmies silencioses: les malalties emergents dels amfibis. L'Atzavara. 2022. (in press). 